Argonne

ANL-21/30

\title{
Corrosion of 347 stainless steel in the presence of uranyl sulfate solution and radiation
}

Chemical \& Fuel Cycle Technologies Division 


\begin{abstract}
About Argonne National Laboratory
Argonne is a U.S. Department of Energy laboratory managed by UChicago Argonne, LLC under contract DE-AC02-06CH11357. The Laboratory's main facility is outside Chicago,

at 9700 South Cass Avenue, Lemont, Illinois 60439. For information about Argonne

and its pioneering science and technology programs, see www.anl.gov.
\end{abstract}

\title{
DOCUMENT AVAILABILITY
}

Online Access: U.S. Department of Energy (DOE) reports produced after 1991 and a growing number of pre-1991 documents are available free at OSTI.GOV (http://www.osti.gov/),

a service of the US Dept. of Energy's Office of Scientific and Technical Information.

Reports not in digital format may be purchased by the public from the National Technical Information Service (NTIS):

U.S. Department of Commerce

National Technical Information Service

5301 Shawnee Road

Alexandria, VA 22312

www.ntis.gov

Phone: (800) 553-NTIS (6847) or (703) 605-6000

Fax: (703) 605-6900

Email: orders@ntis.gov

Reports not in digital format are available to DOE and DOE contractors from the Office of Scientific and Technical Information (OSTI):

U.S. Department of Energy

Office of Scientific and Technical Information

P.O. Box 62

Oak Ridge, TN 37831-0062

www.osti.gov

Phone: (865) 576-8401

Fax: (865) 576-5728

Email: reports@osti.gov

\footnotetext{
Disclaimer

This report was prepared as an account of work sponsored by an agency of the United States Government. Neither the United States Government nor any agency thereof, nor UChicago Argonne, LLC, nor any of their employees or officers, makes any warranty, express or implied, or assumes any legal liability or responsibility for the accuracy, completeness, or usefulness of any information, apparatus, product, or process disclosed, or represents that its use would not infringe privately owned rights. Reference herein to any specific commercial product, process, or service by trade name, trademark, manufacturer, or otherwise, does not necessarily constitute or imply its endorsement, recommendation, or favoring by the United States Government or any agency thereof. The views and opinions of document authors expressed herein do not necessarily state or reflect those of the United States Government or any agency thereof, Argonne National Laboratory, or UChicago Argonne, LLC.
} 
ANL-21/30

\section{Corrosion of 347 stainless steel in the presence of uranyl sulfate solution and radiation}

by

Vineeth K. Gattu', Javier E. Obregon'1, Kevin J. Quigley², Andrei Patapenka², Sergey D. Chemerisov², James P. Byrnes ${ }^{1}$, Derek McLain ${ }^{3}$, Ernesto J. Indacochea ${ }^{1}$, Peter Tkac ${ }^{1}$

${ }^{1}$ Chemical \& Fuel Cycle Technologies Division, Argonne National Laboratory ${ }^{2}$ Experimental Operations \& Facilities Division, Argonne National Laboratory ${ }^{3}$ Strategic Security Sciences Division, Argonne National Laboratory

July 2021 



\section{CONTENTS}

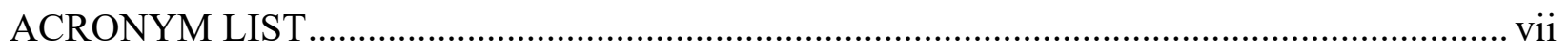

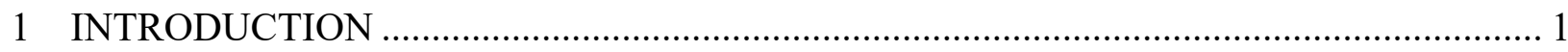

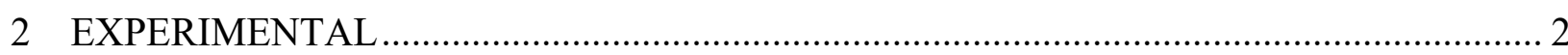

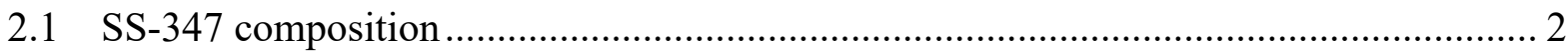

2.2 Preparation of uranyl sulfate solution .................................................................... 2

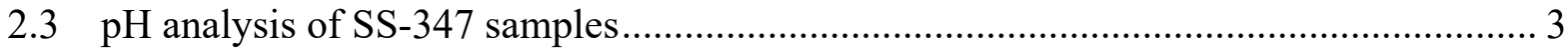

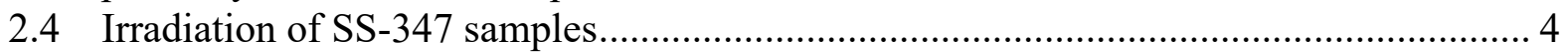

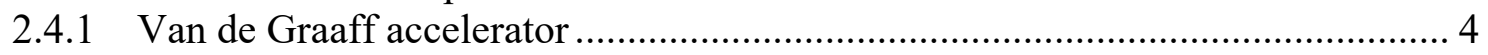

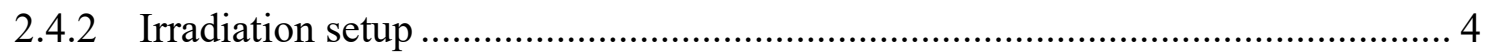

2.5 Determination of radiation dose rate........................................................................ 7

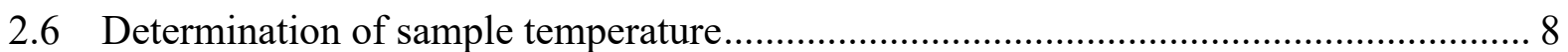

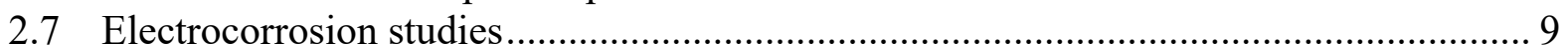

2.7.1 Metallographic characterization.............................................................. 10

2.7.2 Electrochemical corrosion tests ………………........................................... 10

2.8 Monte-Carlo simulations in support of SS-347 corrosion studies ................................. 12

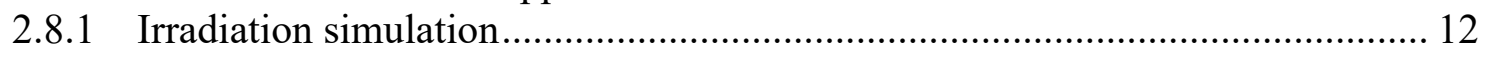

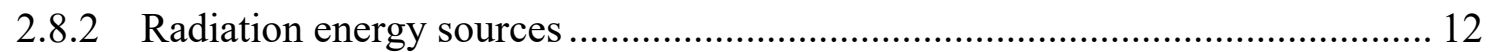

2.9 Surface energy deposition in the active zone vessel................................................... 14

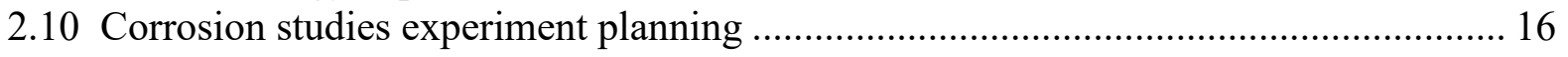

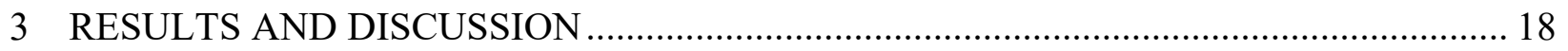

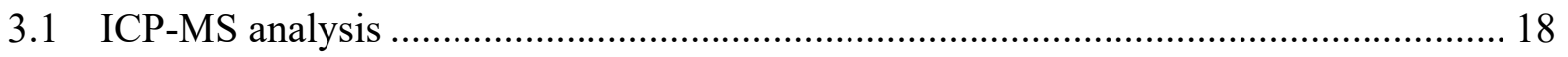

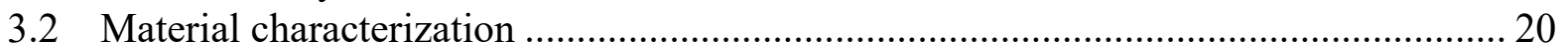

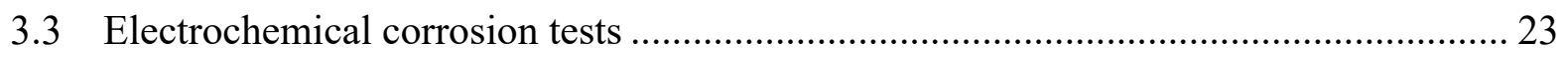

3.3.1 Open-circuit potential measurements in $\mathrm{pH}=1 \mathrm{H}_{2} \mathrm{SO}_{4}$ at $\mathrm{RT}$........................... 23

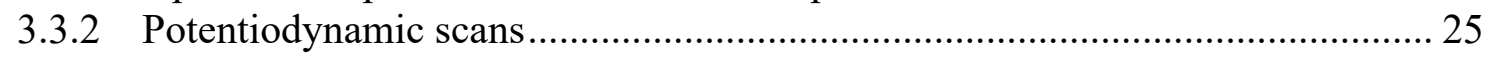

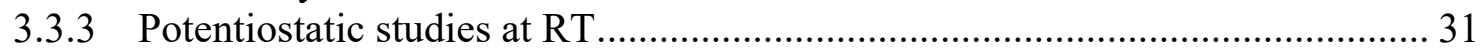

3.3.4 Potentiostatic tests with as-received SS-347 in $\mathrm{H}_{2} \mathrm{SO}_{4}$ solution at

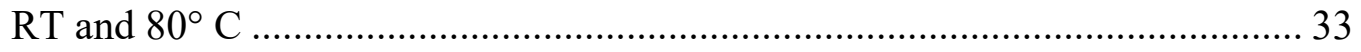

3.3.5 Potentiostatic studies with irradiated SS-347 samples in $\mathrm{UO}_{2} \mathrm{SO}_{4}$

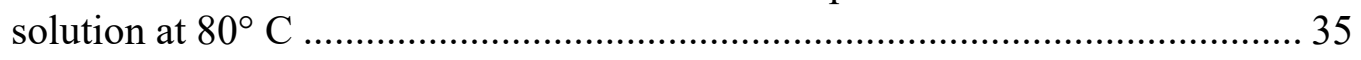

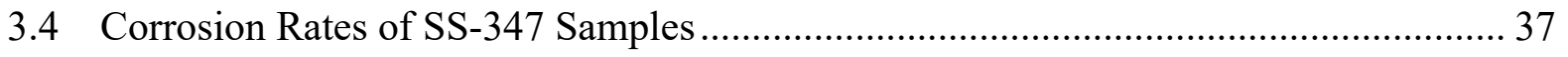

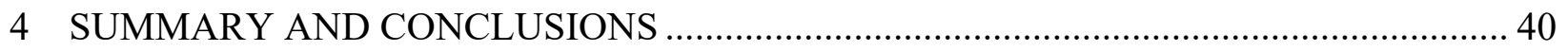

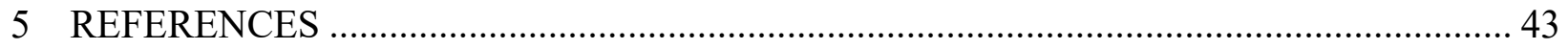




\section{FIGURES}

1 Depleted uranium plate used for preparation of uranyl sulfate solution................................... 2

$2 \mathrm{U}_{3} \mathrm{O}_{8}$ material obtained after oxidation of depleted uranium plates ....................................... 3

3 Conversion of $\mathrm{U}_{3} \mathrm{O}_{8}$ to $\mathrm{UO}_{2} \mathrm{SO}_{4}$ solution: (a) transition from charcoal black to a gray/green color upon addition of $30 \%$ peroxide and $\mathrm{H}_{2} \mathrm{SO}_{4}$; (b) thick yellow solution/suspension formed upon heating at $100^{\circ} \mathrm{C}$; (c) foamy suspension transitioned to thick yellow solution; (d) $\mathrm{UO}_{2} \mathrm{SO}_{4}$ solution after compete

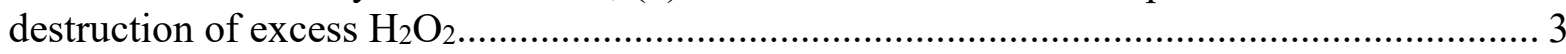

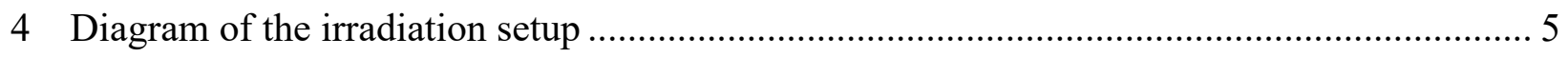

5 Heat exchanger, peristaltic pump and round-bottom flask in the heating mantle .................... 5

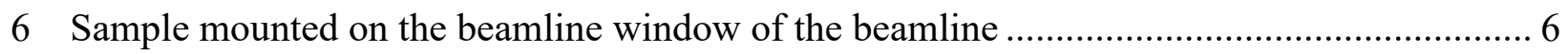

7 Sweep gas line heating mantle and tubing connected to the round-bottom flask ....................... 6

8 Drawing of the quartz tube and fittings that hold the sample in place ..................................... 7

9 Linear Relationship between the $\mu \mathrm{A} \times \mathrm{min}$ and the dose measured from irradiation of $0.06 \mathrm{M}$ oxalic acid with electron beam and sample mounted on the

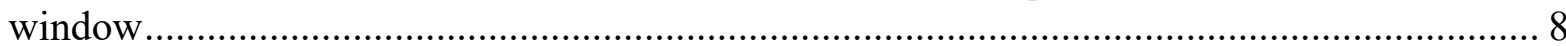

10 As-received SS-347 working microelectrode for electrochemical corrosion tests at room temperature: (a) longitudinal view, (b) as-received cross-section, and

(c) bent-sample cross-section....................................................................................... 9

11 Working electrode holder for flat SS-347 samples and for high-temperature

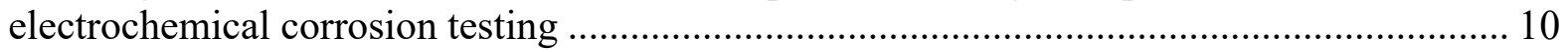

12 Electrochemical corrosion set up for (a) room temperature, and (b) $80^{\circ} \mathrm{C} \ldots \ldots \ldots \ldots \ldots \ldots \ldots \ldots \ldots . . . . . . . .11$

13 Schematic of the high-temperature electrochemical corrosion setup .................................... 11

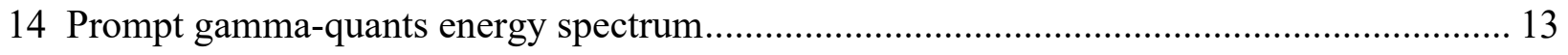

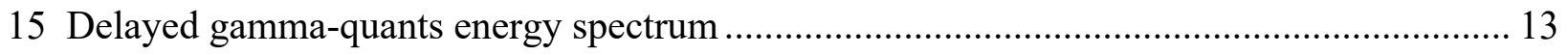

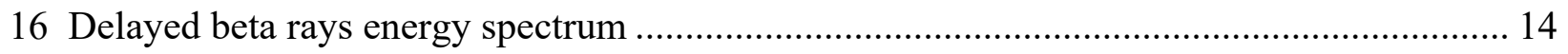

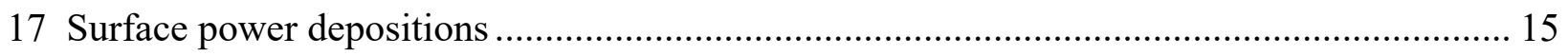

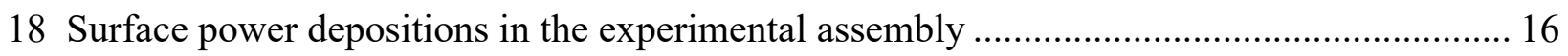

19 SS-347 FE-SEM secondary electron images (a) polished and (b) etched. White

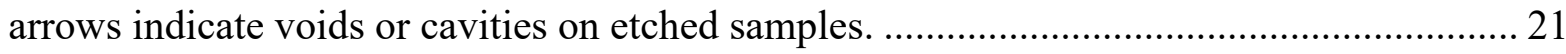

20 FE-SEM in secondary electron mode of SS-347 etched surface. Numbers indicate

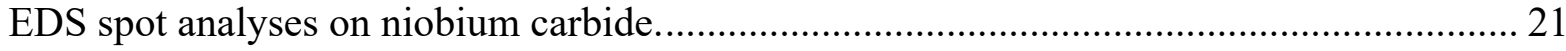

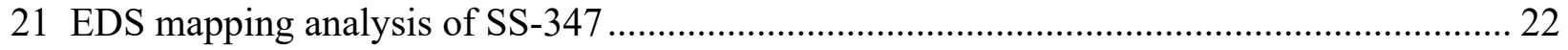

22 EDS line scan analysis covering the matrix (dark phase) and the precipitate (bright phase) 


\section{FIGURES (CONT.)}

23 Long-term exposure OCP measurements of SS-347 in $\mathrm{pH}=1 \mathrm{H}_{2} \mathrm{SO}_{4}$ at RT.

Arrows indicate the potential and time at which the EIS took place.

24 EIS plots of three sections of long-term OCP of SS-347 in $\mathrm{pH}=1 \mathrm{H}_{2} \mathrm{SO}_{4}$ : (a) Bode

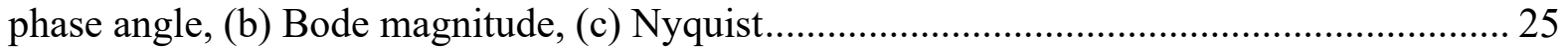

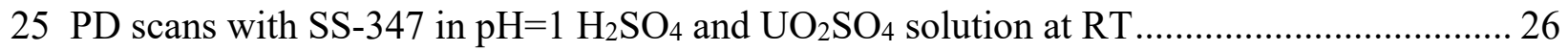

$26 \mathrm{PD}$ scans at $\mathrm{RT}$ and $80^{\circ} \mathrm{C}$ of SS-347 in (a) $\mathrm{pH}=1 \mathrm{M} \mathrm{H}_{2} \mathrm{SO}_{4}$ and (b) $\mathrm{UO}_{2} \mathrm{SO}_{4}$ solutions 26

27 SEM micrographs of SS-347 electrode surfaces after PD scans in $\mathrm{pH}=1 \mathrm{H}_{2} \mathrm{SO}_{4}$ solution at (a) $\mathrm{RT}$ and (b) $80^{\circ} \mathrm{C}$, and in $\mathrm{UO}_{2} \mathrm{SO}_{4}$ solution at (c) $\mathrm{RT}$ and (d) $80^{\circ} \mathrm{C} \ldots \ldots \ldots \ldots . . . .27$

28 PD scans of SS-347 as-received and bent specimens in $\mathrm{pH}=1 \mathrm{H}_{2} \mathrm{SO}_{4}$ at $\mathrm{RT}$..................... 28

29 SS-347 bent specimen after PD scan at $\mathrm{RT}$ in $\mathrm{pH}=1 \mathrm{H}_{2} \mathrm{SO}_{4}$ solution ................................ 28

$30 \mathrm{PD}$ scans of SS-347 as-received and bent specimens in $\mathrm{pH}=1 \mathrm{UO}_{2} \mathrm{SO}_{4}(200 \mathrm{~g} / \mathrm{L})$ at $80^{\circ} \mathrm{C}$

$31 \mathrm{SEM}$ after PD Scan with bent sample in $\mathrm{pH}=1 \mathrm{UO}_{2} \mathrm{SO}_{4}(200 \mathrm{~g} / \mathrm{L})$ at $80^{\circ} \mathrm{C}$ 30

32 PD scans of as-received, bent, and welded SS-347 samples in $\mathrm{pH}=1 \mathrm{UO}_{2} \mathrm{SO}_{4}$ $(200 \mathrm{~g} / \mathrm{L})$ at $80^{\circ} \mathrm{C}$ 30

33 PS measurements at different redox potentials of SS-347 at RT in (a) $0.1 \mathrm{M}$ $\mathrm{H}_{2} \mathrm{SO}_{4}$ and (b) $0.1 \mathrm{M} \mathrm{UO}_{2} \mathrm{SO}_{4}$

34 EIS plots at the 10th day of PS measurements of as-received SS-347 in $\mathrm{pH}=1 \mathrm{H}_{2} \mathrm{SO}_{4}$ (a, c, and e) and $\mathrm{pH}=1 \mathrm{UO}_{2} \mathrm{SO}_{4}(\mathrm{~b}, \mathrm{~d}$, and $\mathrm{f}$ ). Bode phase angle (a and $b$ ), Bode magnitude (c and d), and Nyquist (e and f). 33

35 PS measurements at RT and $80^{\circ} \mathrm{C}$ of SS-347 in $\mathrm{pH}=1 \mathrm{H}_{2} \mathrm{SO}_{4}$ at $0.8 \mathrm{~V}_{\mathrm{SCE}}$ 34

36 SEM images of the as-received SS-347 surface after PS measurement in $\mathrm{pH}=1 \mathrm{H}_{2} \mathrm{SO}_{4}$ at $80^{\circ} \mathrm{C}$ : (a) low magnification (b) high magnification. 34

37 PS tests conducted at $0.8 \mathrm{~V}_{\mathrm{SCE}}$ with SS-347 samples: N-rad, M-rad, H-rad, and Welded $\# 1$ at $\mathrm{RT}$ and $80^{\circ} \mathrm{C}$ in $\mathrm{pH}=1 \mathrm{UO}_{2} \mathrm{SO}_{4}(\mathrm{dU}=200 \mathrm{~g} / \mathrm{L})$ solution 35

38 SEM images of (a) N-rad, (b) M-rad, (c) H-rad SS-347, and (d) Welded \#1 samples after PS tests at $80^{\circ} \mathrm{C}$ in $\mathrm{pH}=1 \mathrm{UO}_{2} \mathrm{SO}_{4}(\mathrm{dU}=200 \mathrm{~g} / \mathrm{L})$ solutions 36

39 EIS curves after PS tests at $0.8 \mathrm{~V}_{\mathrm{SCE}}$ with SS-347 samples at $80^{\circ} \mathrm{C}$ in $\mathrm{pH}=$ $1 \mathrm{UO}_{2} \mathrm{SO}_{4}(\mathrm{dU}=200 \mathrm{~g} / \mathrm{L}$ )solution: (a) Bode magnitude, (b) Bode phase angle, (c and d) Nyquist. 


\section{TABLES}

1 Certified chemical composition of SS-347 ................................................................... 2

2 Equations for calculating dose using oxalic acid dosimeter ....................................... 8

3 List of samples and irradiation conditions for all irradiations performed ........................... 9

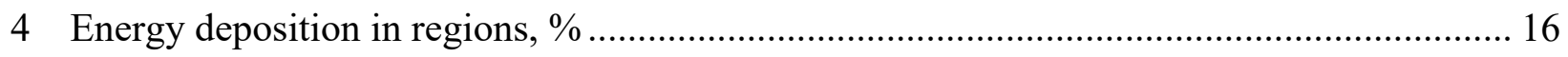

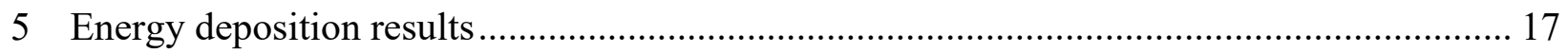

6 ICP-MS data for composition of nonirradiated and irradiated $\mathrm{UO}_{2} \mathrm{SO}_{4}$ solutions ................ 19

7 Concentration of detected metals in irradiated $\mathrm{UO}_{2} \mathrm{SO}_{4}$ solution due to

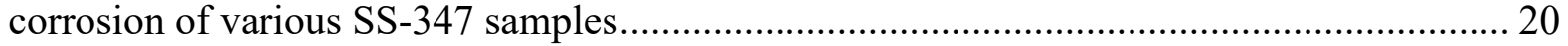

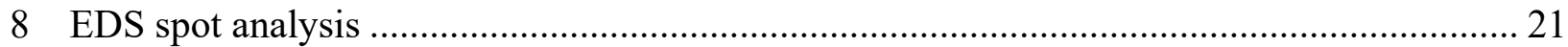

9 Corrosion rates measured in potentiostatic tests with SS-347 samples in $\mathrm{H}_{2} \mathrm{SO}_{4}$ solution .... 38

10 Corrosion rates measured in PS tests with SS-347 samples in $\mathrm{UO}_{2} \mathrm{SO}_{4}$ solution................ 39 


\section{ACRONYM LIST}

$\begin{array}{ll}\text { ECORR } & \begin{array}{l}\text { corrosion potential } \\ \text { electrical discharge machined }\end{array} \\ \text { EDS } & \begin{array}{l}\text { Energy dispersive X-ray spectroscopy } \\ \text { EIS }\end{array} \\ \text { FE-SEM } & \text { fieldrochemical impedance spectroscopy } \\ \text { H-rad } & \text { high radiation SS-347 samples } \\ \text { ICORR } & \begin{array}{l}\text { corrosion current density } \\ \text { ICP-MS }\end{array} \\ \text { M-rad } & \text { medium radively coupled plasma mass spectrometry } \\ \text { N-rad } & \text { as-received nonirradiated SS-347 samples } \\ \text { OCP } & \text { open circuit potential } \\ \text { PD } & \text { potentiodynamic } \\ \text { PS } & \text { potentiostatic } \\ \text { RT } & \text { room temperature } \\ \text { SCE } & \text { saturated calomel electrode } \\ \text { SEM } & \text { stanning electron microscopy } \\ \text { sS } & \text { uranyl sulfate } \\ \text { UO }{ }_{2} S O_{4} & \end{array}$


This page left intentionally blank. 


\title{
CORROSION OF 347 STAINLESS STEEL IN THE PRESENCE OF URANYL SULFATE SOLUTION AND RADIATION
}

\author{
Vineeth K. Gattu ${ }^{1}$, Javier M. Obregon ${ }^{1}$, Kevin J. Quigley ${ }^{2}$, Andrei Patapenka ${ }^{2}$, Sergey D. \\ Chemerisov $^{2}$, James P. Byrnes ${ }^{1}$, Derek McLain ${ }^{3}$, Ernesto J. Indacochea ${ }^{1}$, Peter Tkac ${ }^{1}$ \\ ${ }^{1}$ Chemical and Fuel Cycle Technologies Division, Argonne National Laboratory \\ ${ }^{2}$ Experimental Operations and Facilities Division, Argonne National Laboratory \\ ${ }^{3}$ Strategic Security Sciences Division, Argonne National Laboratory
}

\section{INTRODUCTION}

The U.S. molybdenum 99 (Mo-99) industry is pursuing production of fission-made Mo-99 using a uranium solution such as uranyl sulfate. In this process, uranyl sulfate solution containing low-enriched uranium will be bombarded by neutrons creating Mo-99 and other fission products. During the production, the uranyl sulfate solution will be irradiated until an acceptable activity level of Mo-99 is produced. The uranyl sulfate solution containing Mo-99 and other fission products will then undergo a series of separation steps. First, uranyl sulfate can be separated from Mo-99 using a primary titania column to recover Mo-99, with the uranyl sulfate solution to be used for another irradiation cycle. Then, raffinate from a primary titania column containing Mo-99 can be concentrated and purified using a LEU modified Cintichem process developed by Argonne National Laboratory [1-5].

During irradiation, the temperature of the uranyl sulfate solution can reach near boiling (up to $\sim 80^{\circ} \mathrm{C}$ assumed), causing radiolysis of water and the resultant formation of hydrogen peroxide. Because high-radiation fields will be present during each irradiation cycle, it is important to determine the corrosion rates of SS-347 under such conditions to estimate the life cycle of the target solution vessel. The buildup of corrosion products from the SS components in the uranyl sulfate solution also needs to be well understood because potential accumulation of iron, nickel, and other corrosion products may affect the Mo-99 recovery and purification process.

To study the corrosion rates of SS-347 material under conditions relevant to future Mo-99 production facility, SS-347 coupons in uranyl sulfate solution at $\sim 80^{\circ} \mathrm{C}$ were irradiated using Argonne's Van de Graaff generator, which can generate high-radiation fields without fissioning of uranium or production of activation products. 


\section{EXPERIMENTAL}

\subsection{SS-347 composition}

The composition of the SS-347 as provided by Penn Stainless Products Inc. is shown in Table 1.

TABLE 1 Certified chemical composition of SS-347 (wt \%)

\begin{tabular}{ccccccccccccccc}
\hline Fe & $\mathbf{C r}$ & $\mathbf{N i}$ & $\mathbf{M n}$ & $\mathbf{N b}$ & $\mathbf{M o}$ & $\mathbf{S i}$ & $\mathbf{C u}$ & $\mathbf{C}$ & $\mathbf{N}$ & $\mathbf{T i}$ & $\mathbf{S n}$ & $\mathbf{A l}$ & $\mathbf{P}$ & $\mathbf{S}$ \\
\hline bal. & 17.13 & 9.08 & 1.20 & 0.75 & 0.38 & 0.36 & 0.30 & 0.05 & 0.04 & 0.004 & 0.012 & 0.003 & 0.023 & 0.01 \\
\hline
\end{tabular}

\subsection{Preparation of uranyl sulfate solution}

Depleted uranium metal plates (Figure 1) were oxidized into uranium oxides by heating in the presence of oxygen. The muffle furnace was set to a starting temperature of $450^{\circ} \mathrm{C}$ and kept at this temperature for approximately 2 hours. After that, the temperature was increased each hour incrementally from $450^{\circ} \mathrm{C}$ to $600^{\circ} \mathrm{C}$ to $720^{\circ} \mathrm{C}$ and then to $820^{\circ} \mathrm{C}$. It was kept at $820^{\circ} \mathrm{C}$ for approximately 4 hours to ensure uranium oxides such as $\mathrm{UO}_{3}$ and $\mathrm{UO}_{2}$ decomposed or were converted to $\mathrm{U}_{3} \mathrm{O}_{8}$. Any oxygen lost from heating $\mathrm{U}_{3} \mathrm{O}_{8}$ above $800^{\circ} \mathrm{C}$ was rapidly replaced upon cooling. The muffle furnace was then turned off and the material was allowed to cool.

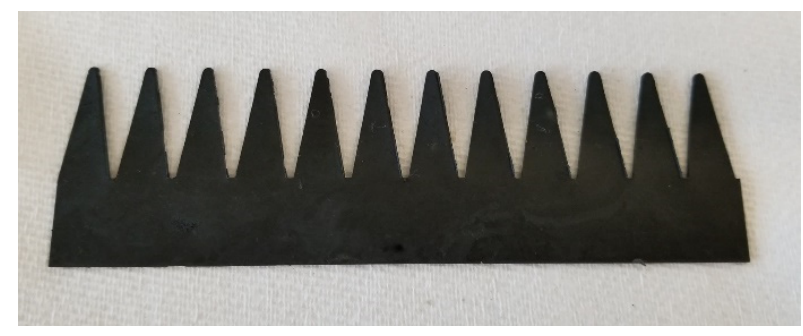

FIGURE 1 Depleted uranium plate used for preparation of uranyl sulfate solution 
Obtained $\mathrm{U}_{3} \mathrm{O}_{8}$ material (Figure 2) was then converted to uranyl sulfate $\left(\mathrm{UO}_{2} \mathrm{SO}_{4}\right)$ solution by adding $30 \%$ hydrogen peroxide $\left(\mathrm{H}_{2} \mathrm{O}_{2}\right)$ and concentrated sulfuric acid $\left(\mathrm{H}_{2} \mathrm{SO}_{4}\right)$. The amount of $\mathrm{H}_{2} \mathrm{SO}_{4}$ needed for the dissolution was determined such that the final solution would have $\mathrm{pH}=1$ at $\sim 200 \mathrm{~g}-\mathrm{U} / \mathrm{L}$.

Upon addition of $\mathrm{H}_{2} \mathrm{O}_{2}$ and $\mathrm{H}_{2} \mathrm{SO}_{4}$, the color of the solution changed from charcoal black to gray/green and thickened. Later, upon continuous heating to keep the temperature of the solution at $\sim 100^{\circ} \mathrm{C}$, yellow precipitate/ suspension formed followed by the solution turning yellow (Figure 3). After complete dissolution of the $\mathrm{U}_{3} \mathrm{O}_{8}$, excess $\mathrm{H}_{2} \mathrm{O}_{2}$ was destroyed by heating the solution until fizzing stopped. Concentrated solution was then diluted by water and the final concentration of the $\mathrm{UO}_{2} \mathrm{SO}_{4}$ solution was determined by inductively coupled plasma mass spectrometry (ICP-MS) analysis. A more detailed description of the conversion of uranium metal to $\mathrm{UO}_{2} \mathrm{SO}_{4}$ solution is found in our previous report [6].

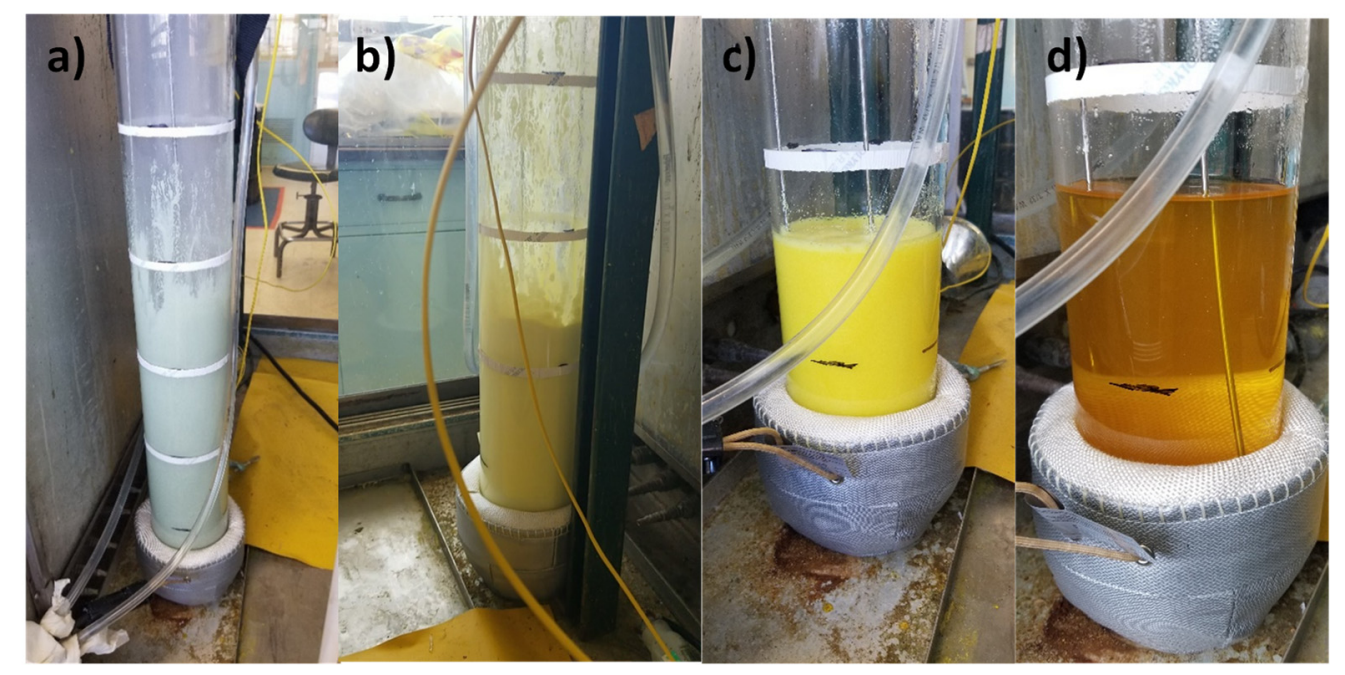

FIGURE 3 Conversion of $\mathrm{U}_{3} \mathrm{O}_{8}$ to $\mathrm{UO}_{2} \mathrm{SO}_{4}$ solution: (a) transition from charcoal black to a gray/green color upon addition of $30 \%$ peroxide and $\mathrm{H}_{2} \mathrm{SO}_{4}$; (b) thick yellow solution/suspension formed upon heating at $100^{\circ} \mathrm{C}$; (c) foamy suspension transitioned to thick yellow solution; (d) $\mathrm{UO}_{2} \mathrm{SO}_{4}$ solution after compete destruction of excess $\mathrm{H}_{2} \mathrm{O}_{2}$

\section{3 pH analysis of SS-347 samples}

Samples were analyzed using a PerkinElmer NexION 2000 ICP-MS spectrometer. The instrument was calibrated with reference samples prepared by diluting the National Institute of Standards and Technology (NIST) traceable standard solutions procured from Ultra Scientific. 
The $\mathrm{pH}$ of the $\mathrm{UO}_{2} \mathrm{SO}_{4}$ solution was determined after calibrating the $\mathrm{pH}$ electrode using $\mathrm{pH}=1$ and $\mathrm{pH}=4$ buffers.

\subsection{Irradiation of SS-347 samples}

\subsubsection{Van de Graaff accelerator}

The low-energy ( $3 \mathrm{MeV}$ ) Van de Graaff accelerator can deliver high levels of electron/photon dose rates to critical components without presenting activation and handling hazards to the irradiated targets. The accelerator was used in electron mode, in which it can deliver up to $80 \mu \mathrm{A}$ current to the $6 \mathrm{~mm} \times 6 \mathrm{~mm}$ full-width-at-half-maximum (FWHM) beam spot on the target.

\subsubsection{Irradiation setup}

An overall schematic of the irradiation setup at the Van de Graaff accelerator is shown in Figure $4.200 \mathrm{ml}$ of $200 \mathrm{~g} / \mathrm{L}$ depleted uranium sulfate solution was preheated in a $500 \mathrm{ml}$ capacity glass vessel using a heating mantle. A heat exchanger designed for this experiment (Figure 5) was used to heat the solution passing through the tubing, using a circulating bath. The $\mathrm{UO}_{2} \mathrm{SO}_{4}$ solution was circulated using a peristaltic pump through PharMed BPT tubing (ColeParmer), through a quartz tube containing an SS-347 sample. BPT tubing is chemically resistant to acids, alkalis, and oxidizing agents, and is rated for use at high temperatures (maximum temperature $132^{\circ} \mathrm{C}$, maximum dynamic temperature $100^{\circ} \mathrm{C}$ ). 


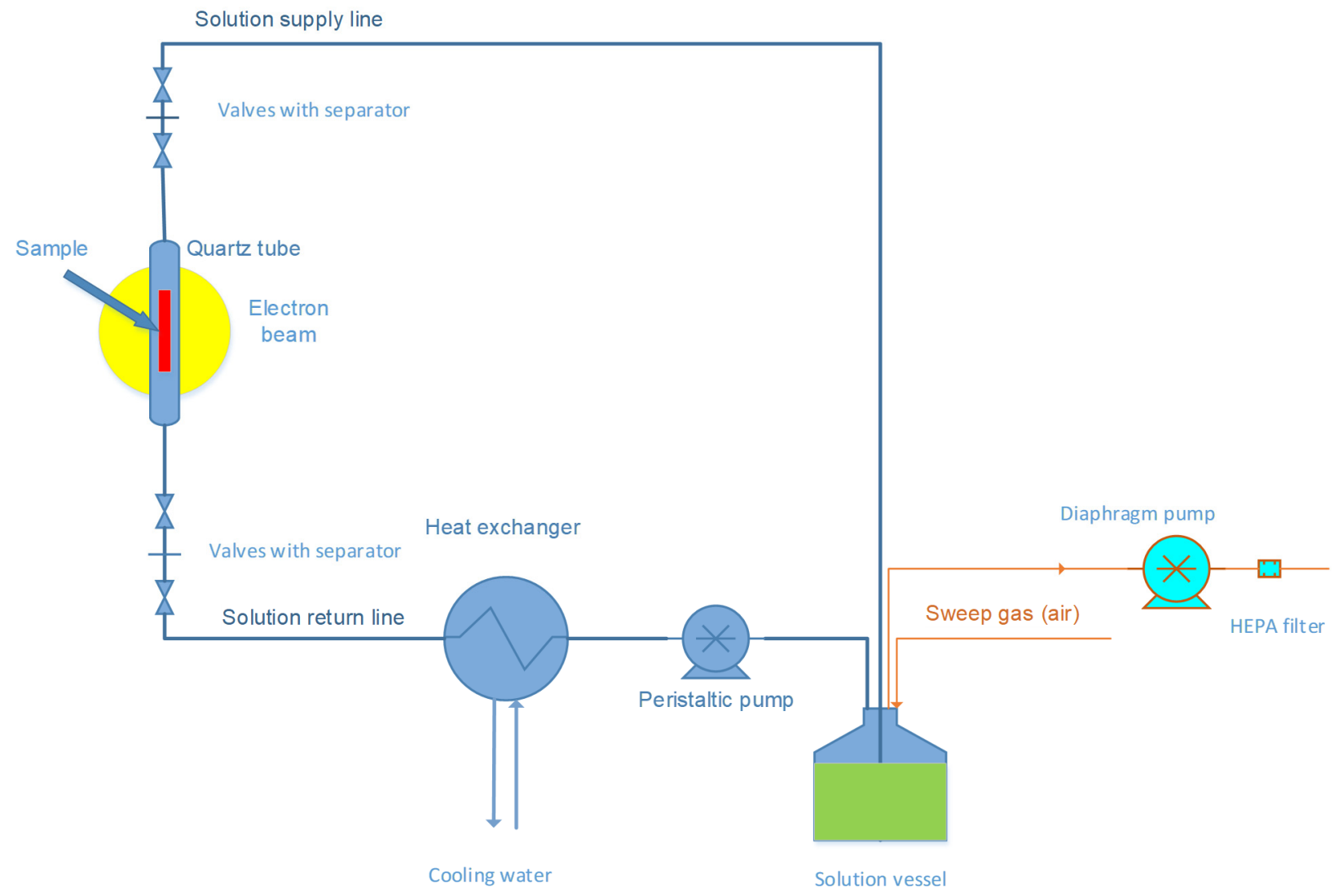

FIGURE 4 Diagram of the irradiation setup

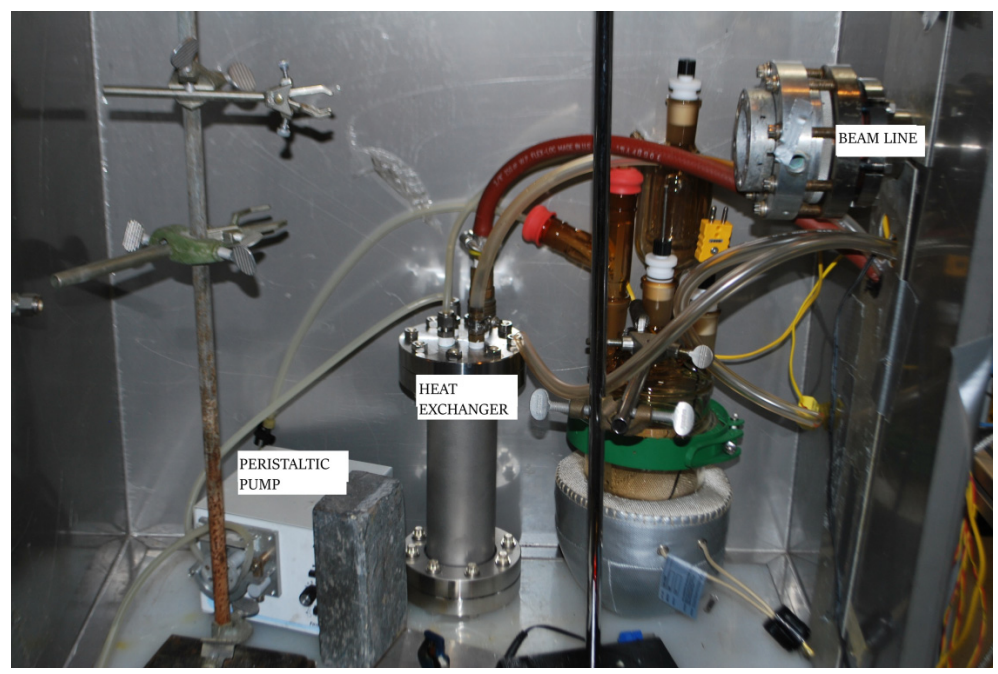

FIGURE 5 Heat exchanger, peristaltic pump and roundbottom flask in the heating mantle 
Temperature was monitored and controlled by a JKem Temperature controller, using Teflon-coated thermocouples (Omega). The quartz tube containing the SS sample was positioned vertically and $\mathrm{UO}_{2} \mathrm{SO}_{4}$ solution flowed from the bottom of the tube. The solution was pulled through the system rather than pumped, to create negative pressure in most of the setup. This ensured that if there were a leak, air would be pulled into the tubing instead of solution spraying out of the system. Water was added periodically to make up for loss from radiolysis and evaporation.

The quartz tube containing the sample was mounted on the window of the beamline (Figure 6). A condenser was attached to the top of the round-bottom vessel. The condenser was cooled by a second circulating bath set at $5^{\circ} \mathrm{C}$. A small vacuum pump pulled air from the enclosure across the air space in the vessel to sweep out hydrogen and oxygen produced by radiolysis (Figure 7). The accelerator was interlocked to the sweep gas flow using a signal from the flow meter to ensure the system would shut down if the vacuum pump failed or was not running.

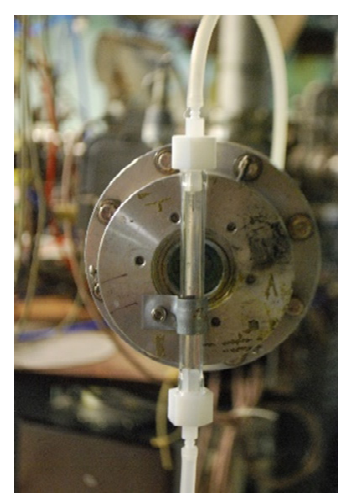

FIGURE 6 Sample mounted on the beamline window of the beamline

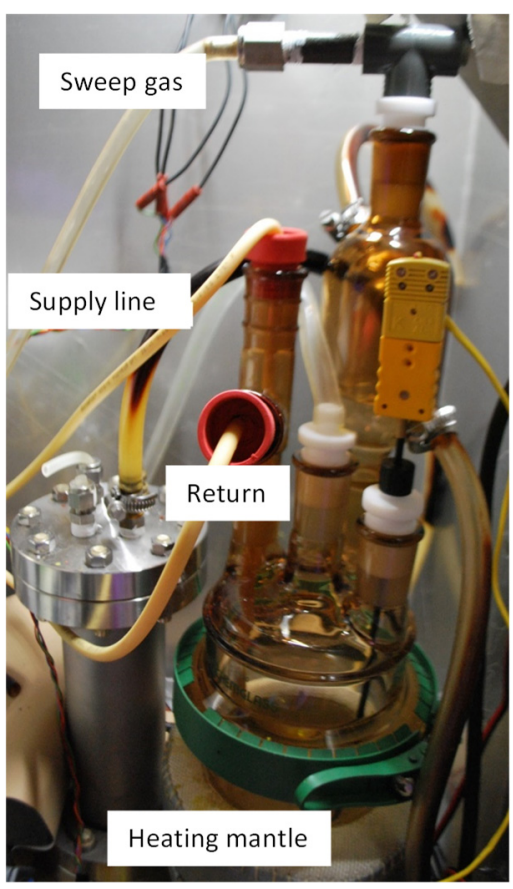

FIGURE 7 Sweep gas line heating mantle and tubing connected to the round-bottom flask 
The SS sample was held inside the quartz tube by plastic holders with a hole for solution flow (Figure 8). Material for the holder was high-density polyethylene, which exhibits good radiation stability and chemical compatibility with hot acidic solution.

After irradiation, the $\mathrm{UO}_{2} \mathrm{SO}_{4}$ solution was pumped back to the round-bottom vessel and water was used to flush the SS sample while still in the quartz tube. The tube was disassembled, and the SS sample was decontaminated before being removed from the enclosure and sent for scanning electron microscopy (SEM) analysis. The $\mathrm{UO}_{2} \mathrm{SO}_{4}$ solution was then pumped out of the vessel and a $2 \mathrm{ml}$ aliquot was submitted for ICP-MS analysis for corrosion products and uranium concentration.

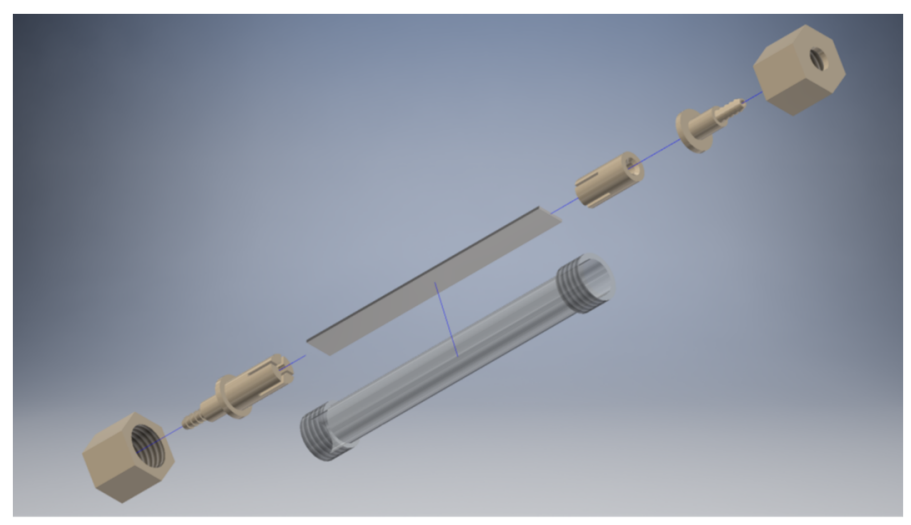

FIGURE 8 Drawing of the quartz tube and fittings that hold the sample in place

\subsection{Determination of radiation dose rate}

Radiation dose rate at the Van de Graaff accelerator was measured using an oxalic acid dosimetry system with geometry similar to that used for irradiation of the SS frits. A quartz tube of the same design (enclosed on the bottom) was filled with $\sim 0.6 \mathrm{M}$ oxalic acid $(2 \mathrm{~mL}$ ), irradiated at 0 degree beamline at $2 \mu \mathrm{A}$ and $3 \mu \mathrm{A}$ current, and mounted on the beam window (Figure 6). Using an oxalic acid dosimeter, the dose was determined by comparing the concentrations of oxalic acid before and after irradiation (as the acid decomposes with irradiation). The concentration of oxalic acid remaining after irradiation was determined by potentiometric titration with a standardized $0.1 \mathrm{M} \mathrm{NaOH}$. The dose was calculated for a decomposition of less than $50 \%$ of the initial concentration of oxalic acid by a standard procedure with a radiochemical yield of $\mathrm{G}=4.9$. The dose can be calculated irrespective of the change in oxalic acid concentration with the equation:

$$
\log D=a \log C+b
$$

where $D$ is the absorbed dose in $\mathrm{eV} / \mathrm{mL} ; C$ is the number of oxalic acid molecules decomposed in $1 \mathrm{~mL}$; and $a$ and $b$ are constants depending on the initial concentration of oxalic acid and the number of moles of oxalic acid decomposed, found in Table 2. 
Results of the dose deposited in the sample as a function of beam current and exposure time are shown in Figure 9. Linear fit to the data gives $2.8 \mathrm{Mrad} / \mu \mathrm{A} \times \mathrm{min}$ slope for the line. This value was used to calculate doses delivered to the samples in all irradiations described in this report.

TABLE 2 Equations for calculating dose using oxalic acid dosimeter

\begin{tabular}{ccc}
\hline Initial $(\mathrm{COOH})_{2}$ & & \\
Concentration $(\mathrm{M})$ & Range of $\log C$ & Dose Equation \\
\hline \multirow{2}{*}{$\mathbf{6 0 0}$} & $18.380<\log C<19.978$ & $\log D=0.999 \log C+1.344$ \\
& $19.978<\log C<20.505$ & $\log D=1.400 \log C-6.668$ \\
\hline
\end{tabular}

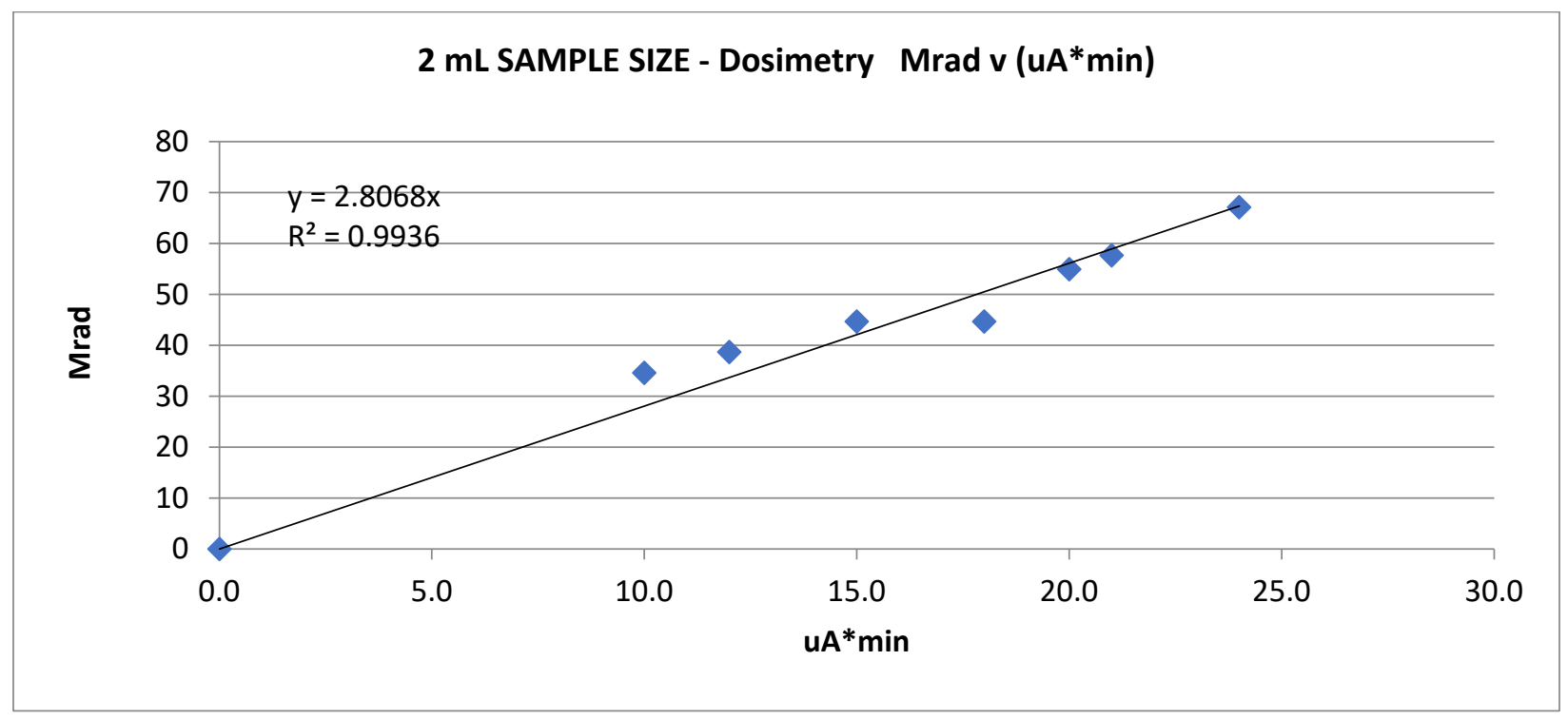

FIGURE 9 Linear Relationship between the $\mu \mathrm{A} \times$ min and the dose measured from irradiation of $0.06 \mathrm{M}$ oxalic acid with electron beam and sample mounted on the window

\subsection{Determination of sample temperature}

The temperature profile was performed using a 1/6-inch thermocouple mounted to the back of an SS frit. The frit was mounted in the quartz tube and placed in the same geometry as the samples. DI water was cooled or heated using the heat exchanger and circulating bath or heated using the heating mantle and pulled through the system over the SS frit. The temperature of the bath and mantle were adjusted to keep the SS frit at $\sim 80^{\circ} \mathrm{C}$ with the varying dose rates (Table 3). 
TABLE 3 List of samples and irradiation conditions for all irradiations performed

\begin{tabular}{lccccc}
\hline \multicolumn{5}{c}{ SS-347 Van de Graaff 3 MeV Irradiations } \\
\hline \multicolumn{1}{c}{ Sample } & $\begin{array}{c}\text { Sample } \\
\text { Temperature }\left({ }^{\circ} \mathrm{C}\right)\end{array}$ & $\begin{array}{c}\text { Current } \\
(\mu \mathrm{A})\end{array}$ & $\begin{array}{c}\text { Dose rate } \\
(\text { Mrad/min) }\end{array}$ & $\begin{array}{c}\text { Accumulated } \\
\text { dose }(\mathrm{Grad})\end{array}$ & $\begin{array}{c}\text { Solution } \\
\text { time at } 80^{\circ} \\
(\mathrm{min})\end{array}$ \\
\hline Welded \#1 & $\sim 80$ & 50 & 139.9 & & 68.55 \\
Machined \#1 & $\sim 80$ & 50 & 139.9 & 11.4 & 81.2 \\
Bent \#1 & $\sim 80$ & 50 & 139.9 & 11.4 & 81.2 \\
EDM \#1* & $\sim 80$ & 50 & 139.9 & 11.4 & 81.2 \\
EDM \#2 & $\sim 80$ & 60 & 168.4 & 13.7 & 81.2 \\
Bent \#2 & $\sim 80$ & 55 & 154.4 & 12.57 & 81.2 \\
EDM \#4 & $\sim 80$ & 5 & 14.03 & 11.6 & 826.5 \\
EDM \#6 & $\sim 80$ & 20 & 56.13 & 47.2 & 841 \\
\hline
\end{tabular}

*EDM $=$ electrical discharge machined

\subsection{Electrocorrosion studies}

As-received, SS-347 plates were machined to dimensions $0.2 \times 0.2 \times 1.5 \mathrm{~cm}^{3}$. As shown in Figure 10a, samples are connected to a lead wire and embedded in epoxy resin. The surface area exposed is about $0.04 \mathrm{~cm}^{2}$ as shown in Figure 10b. Second set of microelectrodes were fabricated following the same procedure. These samples were bent at 90 degrees (see Figure 10c).

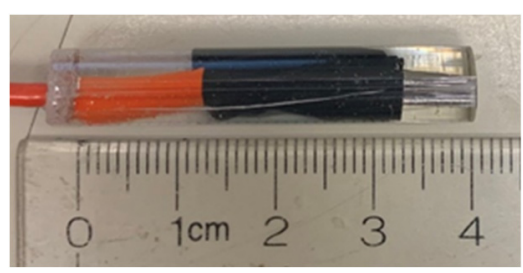

(a)

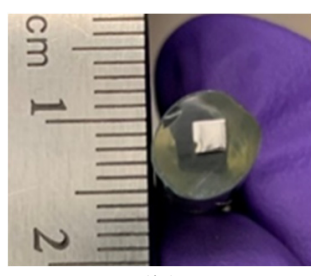

(b)

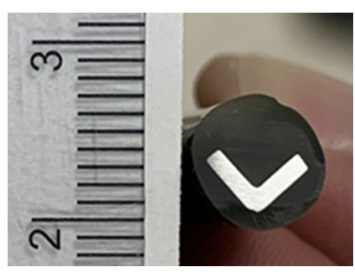

(c)

FIGURE 10 As-received SS-347 working microelectrode for electrochemical corrosion tests at room temperature: (a) longitudinal view, (b) as-received cross-section, and (c) bent-sample crosssection

A third set of SS-347 samples were machined to flat strips with approximate dimensions of $6 \times 70 \times 1.5 \mathrm{~mm}^{3}$ by electrical discharge machining (EDM). These samples were polished to a 1200-grit-paper surface finish following machining. One machined and polished sample was used as a control for baseline comparison. To study the effects of irradiation damage on corrosion behavior, samples were submitted to different levels of irradiation in $\mathrm{UO}_{2} \mathrm{SO}_{4}$ at $80^{\circ} \mathrm{C}$. Smaller specimens of $6 \times 5 \times 1.5 \mathrm{~mm}^{3}$ were cut from both machined/polished and irradiated SS-347 samples for electrochemical corrosion tests. The smaller specimens were fixed inside a custom-designed flat sample holder exposing a surface area of $0.07 \mathrm{~cm}^{2}$, as shown in Figure 11 . 

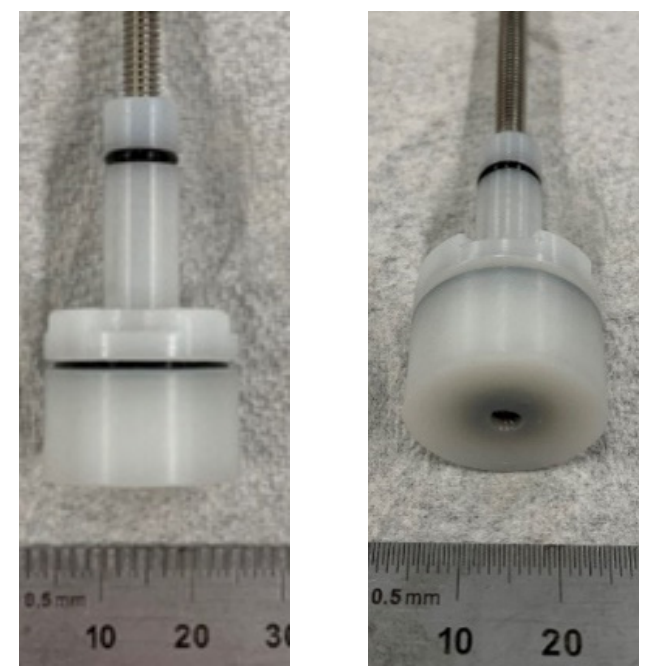

FIGURE 11 Working electrode holder for flat SS-347 samples and for high-temperature electrochemical corrosion testing

\subsubsection{Metallographic characterization}

Samples were embedded in epoxy and prepared using standard metallographic specimen preparation. The working electrodes were prepared by grinding the surface using $\mathrm{SiC}$ paper to a 1200 surface, then polished in a $0.05 \mu \mathrm{m}$ alumina suspension, and ultrasonically cleaned. Material characterization was performed using a field-emission scanning electron microscope (FE-SEM) on the polished and etched samples. Energy dispersive X-ray spectroscopy (EDS) was conducted to identify and quantify phases.

\subsubsection{Electrochemical corrosion tests}

Open circuit potential (OCP) measurements, potentiodynamic (PD) scans, potentiostatic (PS) tests, and electrochemical impedance spectroscopy were

conducted in $\mathrm{pH}=1 \mathrm{H}_{2} \mathrm{SO}_{4}$ and $\mathrm{pH}=1 \mathrm{UO}_{2} \mathrm{SO}_{4}(200 \mathrm{~g}-\mathrm{U} / \mathrm{L})$ at $25^{\circ} \mathrm{C}$ and $80^{\circ} \mathrm{C}$. The electrochemical setup used in all the tests is shown in Figure 12 and a schematic for the hightemperature is shown in Figure 13. SS-347 samples were used as the working electrodes, a graphite rod as the counter electrode, and mercury/mercurous sulfate (MSE) as the reference electrode. All potentials were converted and presented vs. saturated calomel electrode ( $\mathrm{SCE}=$ $+0.400 \mathrm{~V}$ vs. MSE) for convenience.

\section{Long-term OCP was measured for about 28 days in $\mathrm{H}_{2} \mathrm{SO}_{4}$ at $25^{\circ} \mathrm{C}$. Periodic} electrochemical impedance spectroscopy was conducted to measure the surface electrical properties. PD scans were conducted to measure the corrosion potential (ECORR) and corrosion current density (ICORR). The PD scan is also used to identify the active, passive, and transpassive regions. The PD scans were conducted in this study between $-0.25 \mathrm{~V}$ below ECORR to $1.6 \mathrm{VSCE}$ (V vs. SCE). The PS tests are conducted at fixed applied voltages to measure the long-term current densities (i.e., corrosion rates) of the SS-347 samples, which represent various imposed redox conditions that could occur due to changing environmental conditions (redox, chemistry, $\mathrm{pH}$, temperature) in the solution during Mo-99 production. Previous modeling work on speciation, precipitate formation, and the chemical effects of steel corrosion showed that a redox value of $1.1 \mathrm{~V}_{\mathrm{SHE}}(\sim 0.8 \mathrm{VSCE})$ [7] could be generated in the solution. In this study, PS tests were conducted above and below these expected process redox conditions. 


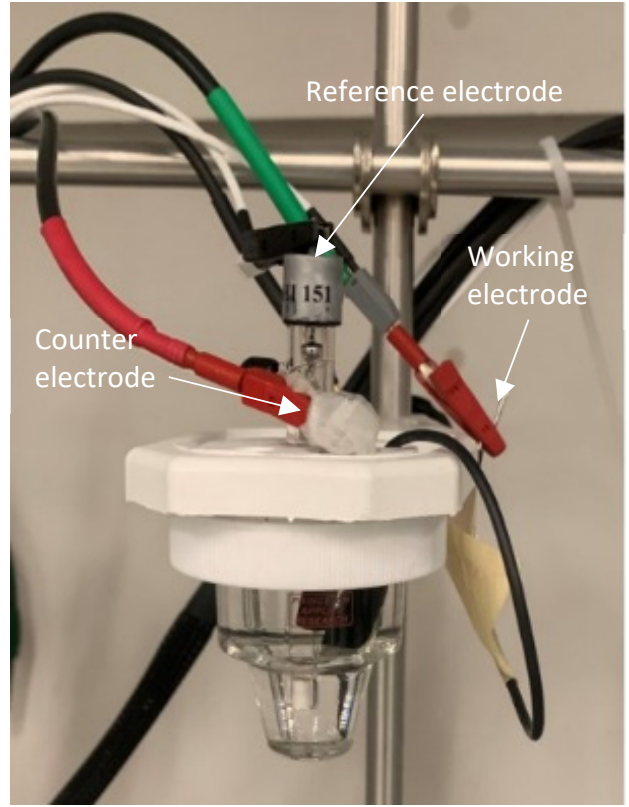

(a)

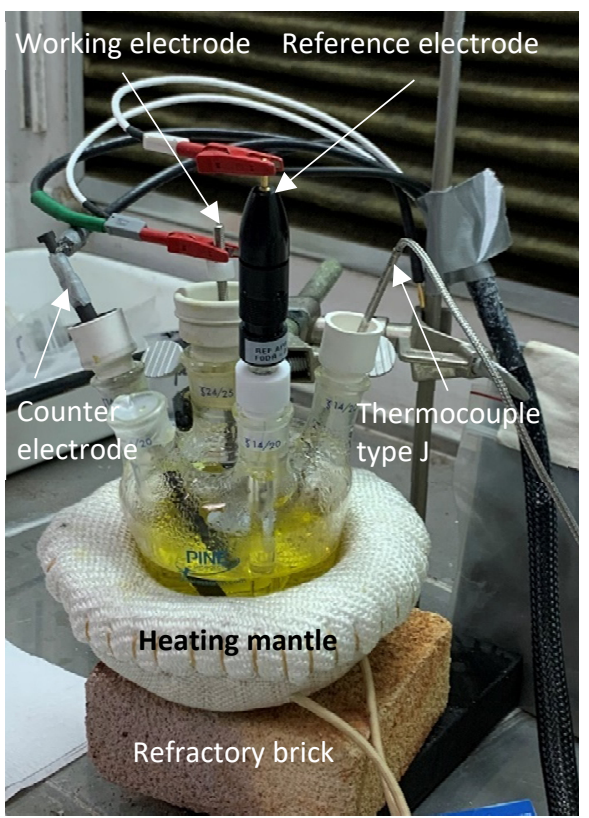

(b)

FIGURE 12 Electrochemical corrosion set up for (a) room temperature, and (b) $80^{\circ} \mathrm{C}$

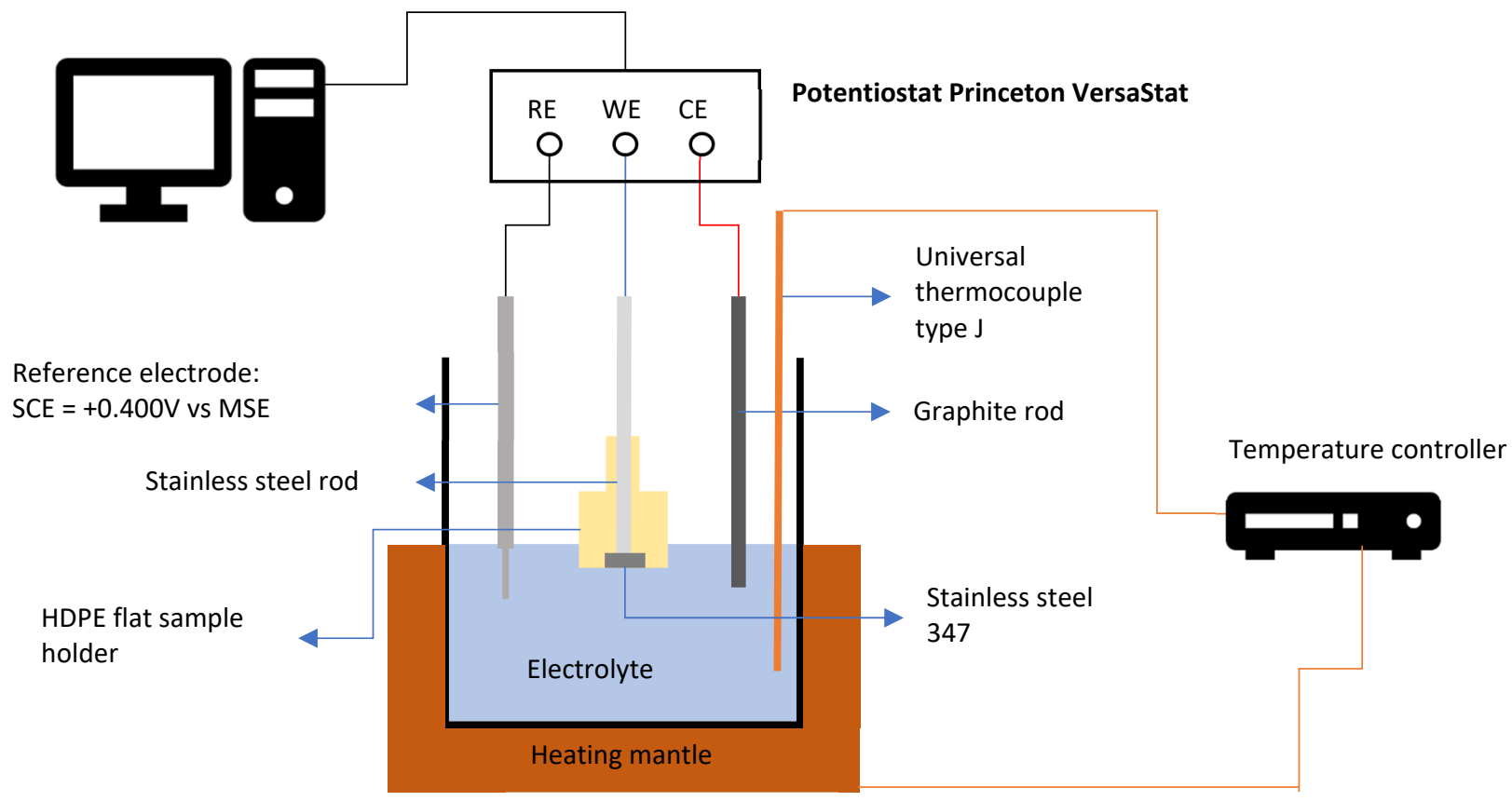

FIGURE 13 Schematic of the high-temperature electrochemical corrosion setup 


\subsection{Monte-Carlo simulations in support of SS-347 corrosion studies}

\subsubsection{Irradiation simulation}

Monte-Carlo studies were performed to provide estimations of radiation energy deposition in uranium solution and the SS-347 active zone's vessel during a Mo-99 facility operations. The estimated energy deposition values were then used to plan the SS-347 corrosion experiment.

The uranium fission reactions were simulated with MCNP Monte-Carlo code [8]. Total fission density was estimated in the range of $(1.56-3.02) \times 10^{10}$ fissions $/ \mathrm{sec} . / \mathrm{cm}^{3}$.

Transport of fission fragments in the solution and SS-347 was simulated with SRIM code [9], and transport of delayed gamma quants and beta rays was simulated with FLUKA code [10].

\subsubsection{Radiation energy sources}

The total average energy released by the fission of the nucleus includes kinetic energy of fission fragments, kinetic energies of prompt and delayed gamma and beta rays, and kinetic energies of prompt and delayed neutrons and antineutrinos. Sources that may impact energy depositions are described below. All simulations assumed uniform distribution of fission events - this conservative approach overestimates the impact of radiation on the construction materials.

Fission fragments - The spatial distribution of fission fragments was simulated using the following assumptions:

1. Fission events were randomly and uniformly distributed in the $\mathrm{UO}_{2} \mathrm{SO}_{4}$ layer.

2. A-Z fission fragments distribution and kinetic energies were obtained with MCNP (thermal fission of $\mathrm{U}^{235}$ ).

3. Angular distribution was calculated from classical kinematics.

4. Only one fragment from a fission event in the forward hemisphere was under consideration $(0<\boldsymbol{\varphi}<180)$.

Prompt fission gamma quants - The following assumptions were used in simulating prompt fission gamma sources:

1. The energy spectrum [11] had average and median energies of 1.0 and $0.6 \mathrm{MeV}$, respectively (shown in Figure 14).

2. The total number of photons was normalized on 8.32 gammas/fission.

3. Fission density $1.56 \times 10^{10}$ fission $/ \mathrm{sec} . / \mathrm{cm}^{3}$. 


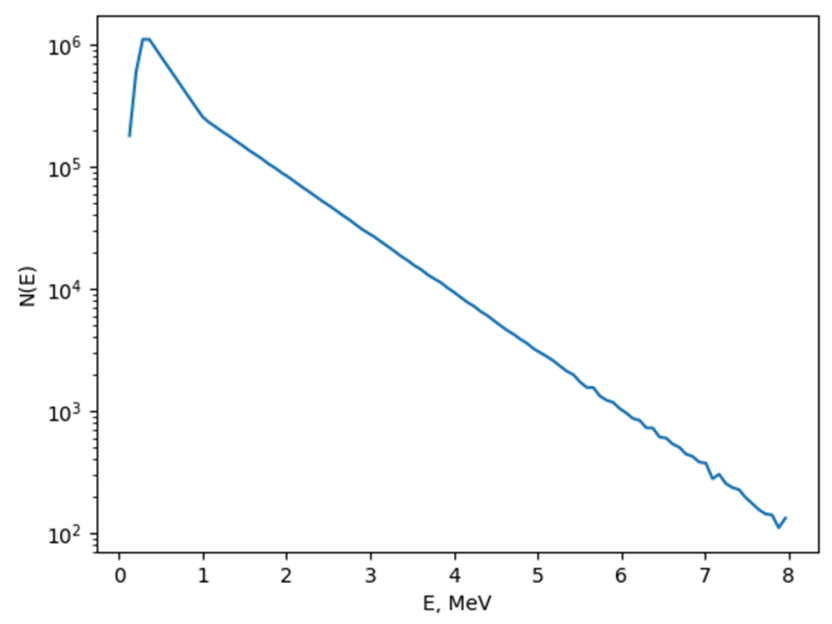

FIGURE 14 Prompt gamma-quants energy spectrum

Fission fragments gamma quants - the fission fragments gamma quants (delayed gamma quant, 1-20,000 sec.) distribution source was simulated with the following assumptions:

1. The energy spectrum analytical representation used was taken from Katakura \& England [12] (shown in Figure 15).

2. Fission density $1.56 \times 10^{10}$ fission $/ \mathrm{sec} . / \mathrm{cm}^{3}$.

3. Total gamma emitted energy was $3.25 \mathrm{MeV} /$ fission [13].

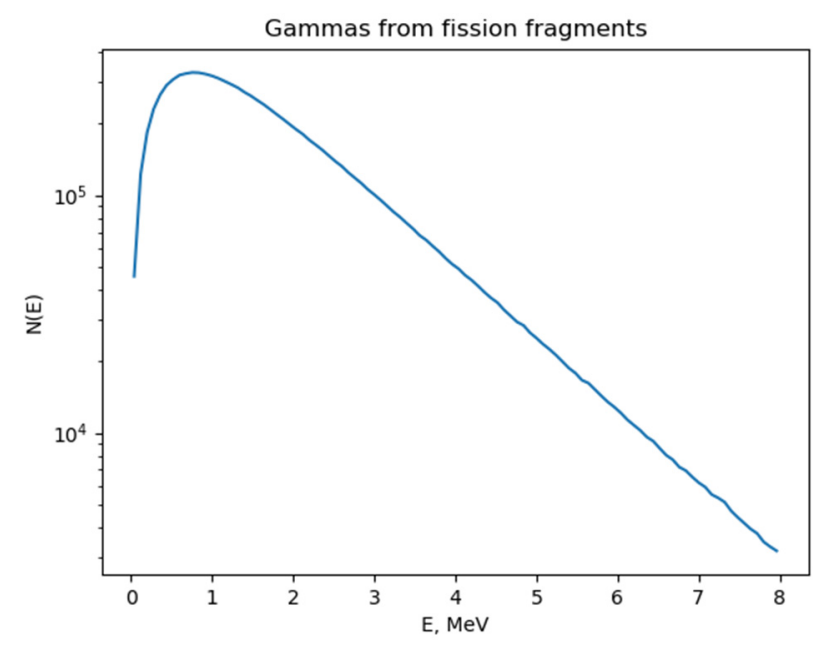

FIGURE 15 Delayed gamma-quants energy spectrum

Fission fragments beta rays - Beta rays from fission fragments had the energy spectrum shown in Figure 16. Its analytical representation can be found in Avignone et al. [14]. The total number of beta particles per fission was $\sim 6.06$, distributed uniformly over the active volume. 


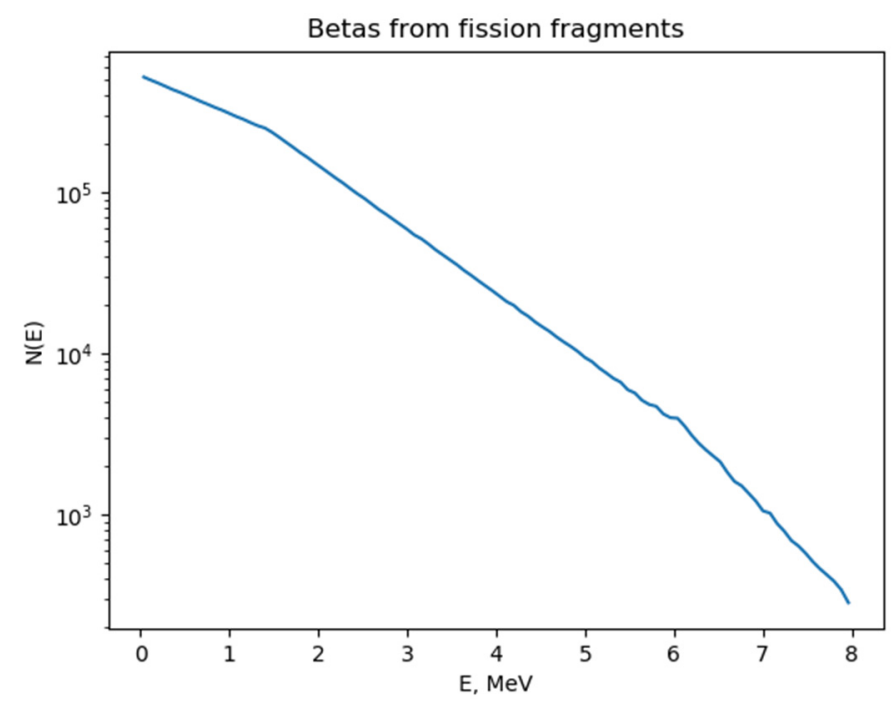

FIGURE 16 Delayed beta rays energy spectrum

\subsection{Surface energy deposition in the active zone vessel}

Average energy/power deposition profiles near the lateral inner surface of the vessel are shown in Figure 17. The number of fissions for nominal range of power is in the range of $(1.56-3.02) \times 10^{10}$ fissions $/ \mathrm{sec} . / \mathrm{cm}^{3}$. The normalization factor for the data presented in Figure 17 is $1.56 \times 10^{10}$ fissions $/ \mathrm{sec} . / \mathrm{cm}^{3}$.

In Figure 17 the border between the solution and the vessel shell is 0 . Negative depth values correspond to $\mathrm{UO}_{2} \mathrm{SO}_{4}$ solution, and positive values are for SS-347.

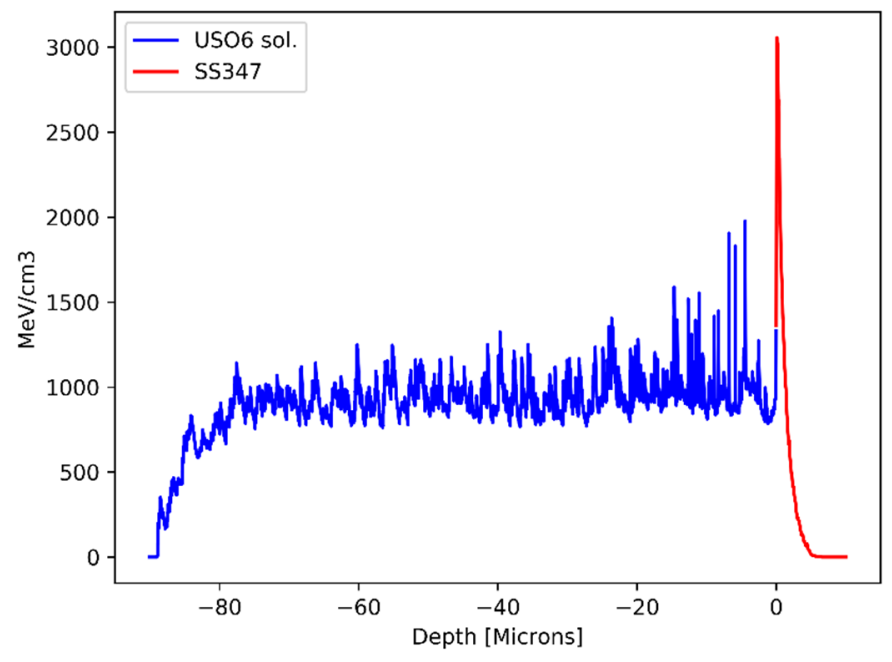

\section{Fission fragments}

Average power deposition ( $1 \mu \mathrm{m}$ surface layer)

$\mathrm{UO}_{2} \mathrm{SO}_{4}$ solution: $1.72 \mathrm{E}-5 \mathrm{~W} / \mathrm{cm}^{2}$

SS-347: 4.35E-5 W/cm² 


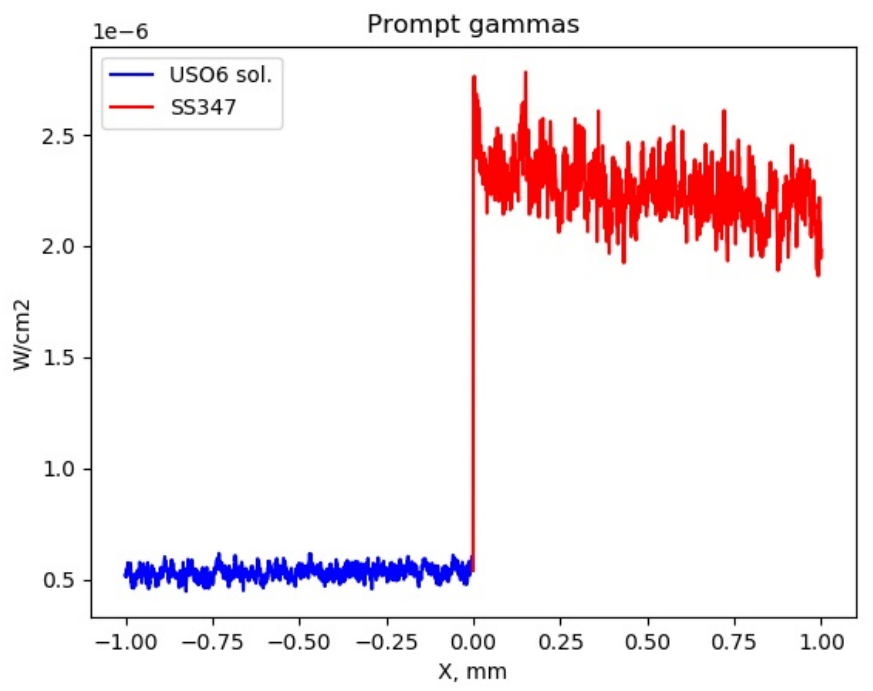

\section{Prompt $\gamma$ quants}

Average power deposition (1 $\mathrm{\mu m}$ surface layer)

$\mathrm{UO}_{2} \mathrm{SO}_{4}$ solution: 5.40E-7 W/cm ${ }^{2}$

SS-347: 2.69E-6 W/cm ${ }^{2}$

Fission fragments $\gamma$-rays

Average power deposition (1 $\mu \mathrm{m}$ surface layer)

$\mathrm{UO}_{2} \mathrm{SO}_{4}$ solution: $2.38 \mathrm{E}-7 \mathrm{~W} / \mathrm{cm}^{2}$

SS-347: $1.15 \mathrm{E}-6 \mathrm{~W} / \mathrm{cm}^{2}$

Fission fragments $\beta$-rays

Average power deposition (1 $\mathrm{\mu m}$ surface layer)

$\mathrm{UO}_{2} \mathrm{SO}_{4}$ solution: $6.26 \mathrm{E}-7 \mathrm{~W} / \mathrm{cm}^{2}$

SS-347: 2.84E-6 W/cm ${ }^{2}$

FIGURE 17 Surface power depositions 
The simulations concluded that fission fragments are dominant in surface energy deposition ( $>92 \%$ for the solution and $>86 \%$ for SS-347).

\subsection{Corrosion studies experiment planning}

To plan the irradiation experiment we simulated the experimental assembly. The assembly and the irradiated sample are shown in detail in Figure 6. The source of primary particles was a $3 \mathrm{MeV}$ electron beam with Gaussian shape $\left(\mathrm{FWHM}_{\mathrm{x}}=6 \mathrm{~mm}\right)$ and total power of $180 \mathrm{~W}$. Simulated materials are listed below:

1. Quartz container: $\mathrm{SiO}_{2}$, density $2.32 \mathrm{~g} / \mathrm{cc}$;

2. Solution $\mathrm{USO}_{6}(200 \mathrm{~g}$ of $\mathrm{U} / \mathrm{L})$ : $\mathrm{USO}_{6}+\mathrm{H}_{2} \mathrm{O}$;

3. Sample: SS-347, density $7.96 \mathrm{~g} / \mathrm{cc}$.

Total beam energy deposition is given in Table 4. Spatial distribution and surface energy deposition in the experimental assembly are shown in Figure 18. Maximal surface power deposition ( $1 \mu \mathrm{m}$ surface layer) is $2.5 \mathrm{E}-2 \mathrm{~W} / \mathrm{cm}^{2}$ for the solution and $1.2 \mathrm{E}-1 \mathrm{~W} / \mathrm{cm}^{2}$ for the SS-347 sample. Since the overall SS-347 sample size is much bigger than the beam spot (Figure 6), the average (over the sample surface) values of the energy depositions are one order of magnitude lower: $2.53 \mathrm{E}-2 \mathrm{~W} / \mathrm{cm}^{2}$ and $1.22 \mathrm{E}-2 \mathrm{~W} / \mathrm{cm}^{2}$ for the solution and sample, respectively.

TABLE 4 Energy deposition in regions, \%

\begin{tabular}{lcc}
\hline \multicolumn{1}{c}{ Region } & $\begin{array}{c}\text { With SS-347 } \\
\text { sample }\end{array}$ & $\begin{array}{c}\text { Without SS-347 } \\
\text { sample }\end{array}$ \\
\hline SS-347 sample & 25.7 & - \\
Solution & 36.0 & 56.3 \\
Container & 23.2 & 27.1 \\
Escaping the system & 15.1 & 16.6 \\
\hline
\end{tabular}
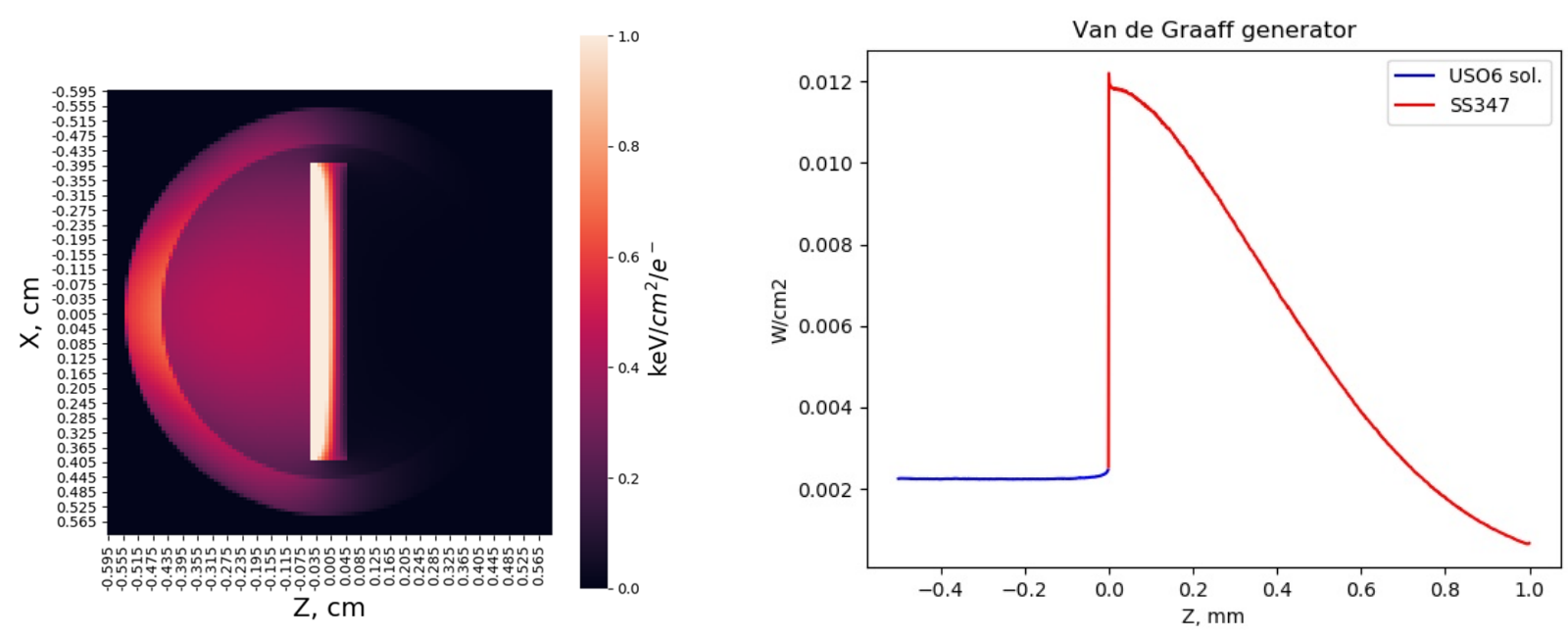

FIGURE 18 Surface power depositions in the experimental assembly 
Since fission fragments dominate the formation of absorbed doses, we can do some simple estimations to check the results. The absorbed dose rate from fission was estimated to be $2.4 \mathrm{Mrad} / \mathrm{min}$ in the irradiation zone based on desired moly output from a moly production facility. A factor of $1 / 2$ must be applied to this number, since only one in two fission fragments has a direction toward the border between the solution and the vessel wall.

As a summary, all results for surface ionizing energy deposition are given in Table 5. From the point of surface ionizing energy absorption rate, the Van de Graaff accelerator provides excellent capabilities (100-250 times higher rate than the real production assembly at nominal operation power). The average surface dose accumulated during a 6-day irradiation cycle was $3.3 \mathrm{Grad}$ for the vessel and $8 \mathrm{Grad}$ for the active volume. At Van de Graaff accelerator, the dose delivered to sample is determined by measuring the concentration change of oxalic acid (as described previously). Therefore, only the dose delivered to solution can be measured using oxalic acid dosimetry. Based on the data in Table 5, the difference between calculated dose rate in uranium solution $\left(\sim 125 \mathrm{MRad} / \mathrm{min} / \mathrm{cm}^{2}\right)$ and SS sample $\left(\sim 92 \mathrm{MRad} / \mathrm{min} / \mathrm{cm}^{2}\right)$ is a factor of 1.35. To deliver a dose of $8 \mathrm{GRad}$ to SS sample at the VDG configuration, dose delivered to solution needs to be $\sim 11$ Grad.

TABLE 5 Energy deposition results

\begin{tabular}{|c|c|c|c|}
\hline & \multirow[b]{2}{*}{ Ionization energy source } & \multicolumn{2}{|c|}{$\begin{array}{c}\text { Average power deposition } \\
\text { in the surface layer, } \\
\mathrm{W} / \mathrm{cm}^{2}\left(\mathrm{Mrad} / \mathrm{min} / \mathrm{cm}^{2}\right)\end{array}$} \\
\hline & & $\mathrm{UO}_{2} \mathrm{SO}_{4}$ solution & SS-347 sample \\
\hline $\begin{array}{l}\text { active volume } \\
\text { ( } 85 \mathrm{~kW} \text { fission power) }\end{array}$ & $\begin{array}{l}\text { Prompt gamma rays from fission events } \\
\text { Gamma rays from fission fragments } \\
\text { Beta rays from fission fragments } \\
\text { Fission fragments }\end{array}$ & $\begin{array}{l}5.40 \mathrm{E}-7(0.027) \\
2.38 \mathrm{E}-7(0.012) \\
6.26 \mathrm{E}-7(0.031) \\
1.72 \mathrm{E}-5(0.846)\end{array}$ & $\begin{array}{l}2.69 \mathrm{E}-6(0.020) \\
1.15 \mathrm{E}-6(0.009) \\
2.84 \mathrm{E}-6(0.022) \\
4.34 \mathrm{E}-5(0.330)\end{array}$ \\
\hline & & \multicolumn{2}{|c|}{$\begin{array}{c}\text { Average power deposition over } 1 \mathrm{c} \\
\text { beam spot of } 2.5 \times 2.5 \mathrm{~mm}\end{array}$} \\
\hline $\begin{array}{l}\text { Argonne experimental setup } \\
\text { (180 W beam power) }\end{array}$ & $3 \mathrm{MeV}$, Van de Graaff accelerator & $2.53 \mathrm{E}-3(124.8)$ & $1.22 \mathrm{E}-2(92.4)$ \\
\hline
\end{tabular}




\section{RESULTS AND DISCUSSION}

\subsection{ICP-MS analysis}

$\mathrm{UO}_{2} \mathrm{SO}_{4}$ solution before and after irradiation was submitted for ICP-MS analysis to determine the initial level of impurities and whether any increased concentration of SS-347 components could be detected after irradiation of SS-347 samples in $\mathrm{UO}_{2} \mathrm{SO}_{4}$ solution. Table 6 summarizes the ICP-MS data for these samples. 
TABLE 6 ICP-MS data for composition of nonirradiated and irradiated $\mathrm{UO}_{2} \mathrm{SO}_{4}$ solutions

\begin{tabular}{|c|c|c|c|c|c|c|c|c|c|c|c|c|}
\hline Sample & $\mathrm{Al}$ & $\mathrm{Si}$ & $\mathrm{Ti}$ & $\mathrm{Cr}$ & $\mathrm{Mn}$ & $\mathrm{Fe}$ & $\mathrm{Co}$ & $\mathrm{Ni}$ & $\mathrm{Cu}$ & $\mathrm{Nb}$ & Mo & $\mathrm{U}$ \\
\hline Unit & $\mathrm{ppb}$ & $\mathrm{ppb}$ & $\mathrm{ppb}$ & $\mathrm{ppb}$ & $\mathrm{ppb}$ & $\mathrm{ppb}$ & $\mathrm{ppb}$ & $\mathrm{ppb}$ & $\mathrm{ppb}$ & $\mathrm{ppb}$ & $\mathrm{ppb}$ & $\mathrm{g} / \mathrm{L}$ \\
\hline $\begin{array}{l}\text { Nonirradiated } \\
\text { U solution }\end{array}$ & $<1.33 \mathrm{E}+03$ & $<9.13 \mathrm{E}+04$ & $8.43 \mathrm{E}+03$ & $<684$ & $1.43 \mathrm{E}+03$ & $2.12 \mathrm{E}+04$ & $<84.7$ & $2.31 \mathrm{E}+03$ & $4.74 \mathrm{E}+03$ & $<741$ & $<696$ & 206 \\
\hline Welded & $<3.77 \mathrm{E}+03$ & $<9.13 \mathrm{E}+04$ & $1.12 \mathrm{E}+04$ & $1.06 \mathrm{E}+03$ & $2.06 \mathrm{E}+03$ & $3.74 \mathrm{E}+04$ & $<92.3$ & $4.87 \mathrm{E}+03$ & $1.13 \mathrm{E}+04$ & $<763$ & $<715$ & 262 \\
\hline Bent \#1 & $<2.14 \mathrm{E}+03$ & $<9.13 \mathrm{E}+04$ & $1.02 \mathrm{E}+04$ & $<805$ & $1.77 \mathrm{E}+03$ & $2.71 \mathrm{E}+04$ & $<80.0$ & $3.03 \mathrm{E}+03$ & $6.94 \mathrm{E}+03$ & $<771$ & $<625$ & 239 \\
\hline Bent \#2 & $<2.50 \mathrm{E}+03$ & $<9.13 \mathrm{E}+04$ & $9.64 \mathrm{E}+03$ & $<684$ & $1.62 \mathrm{E}+03$ & $2.48 \mathrm{E}+04$ & $<80.0$ & $2.89 \mathrm{E}+03$ & $6.79 \mathrm{E}+03$ & $<697$ & $<572$ & 222 \\
\hline EDM \#1 & $<4.29 \mathrm{E}+03$ & $<9.13 \mathrm{E}+04$ & $9.45 \mathrm{E}+03$ & $<950$ & $1.79 \mathrm{E}+03$ & $2.65 \mathrm{E}+04$ & $<80.0$ & $2.94 \mathrm{E}+03$ & $6.91 \mathrm{E}+03$ & $<710$ & $<593$ & 226 \\
\hline EDM \#2 & $<2.05 \mathrm{E}+03$ & $<9.13 \mathrm{E}+04$ & $9.20 \mathrm{E}+03$ & $<684$ & $1.45 \mathrm{E}+03$ & $2.18 \mathrm{E}+04$ & $<117$ & $2.56 \mathrm{E}+03$ & $5.30 \mathrm{E}+03$ & $<640$ & $<631$ & 220 \\
\hline Machined & $<1.98 \mathrm{E}+03$ & $<9.13 \mathrm{E}+04$ & $9.08 \mathrm{E}+03$ & $<684$ & $1.49 \mathrm{E}+03$ & $2.27 \mathrm{E}+04$ & $<80.0$ & $2.52 \mathrm{E}+03$ & $5.26 \mathrm{E}+03$ & $<622$ & $<523$ & 212 \\
\hline EDM4 & $<5.94 \mathrm{E}+03$ & $<1.61 \mathrm{E}+05$ & $9.70 \mathrm{E}+03$ & $<1.31 \mathrm{E}+03$ & $1.63 \mathrm{E}+03$ & $2.56 \mathrm{E}+04$ & $<54.3$ & $2.44 \mathrm{E}+03$ & $4.84 \mathrm{E}+03$ & $<445$ & $<650$ & 213 \\
\hline EDM6 & $<8.04 \mathrm{E}+03$ & $<1.44 \mathrm{E}+05$ & $1.37 \mathrm{E}+04$ & $<2.28 \mathrm{E}+03$ & $2.47 \mathrm{E}+03$ & $3.69 \mathrm{E}+04$ & $<40.0$ & $3.75 \mathrm{E}+03$ & $8.27 \mathrm{E}+03$ & $<355$ & $<429$ & 341 \\
\hline
\end{tabular}


As shown in Table 6, irradiation and heating increased uranium concentration in the solution; this occurred due to a loss of water vapor. Table 7 shows the increased concentration of metals observed in irradiated SS-347 samples after correcting for the volume difference. Almost all samples show increased concentration of $\mathrm{Fe}, \mathrm{Ni}, \mathrm{Mn}, \mathrm{Cu}$, and $\mathrm{Ti}$. The highest increase in concentration of these metals was observed for $\mathrm{UO}_{2} \mathrm{SO}_{4}$ solution with irradiated welded SS-347, but all samples show the presence of corrosion products.

TABLE 7 Concentration (ppb) of detected metals in irradiated $\mathrm{UO}_{2} \mathrm{SO}_{4}$ solution due to corrosion of various SS-347 samples

\begin{tabular}{lcccccc}
\hline \multicolumn{1}{c}{ Sample } & $\mathrm{Ti}$ & $\mathrm{Cr}$ & $\mathrm{Mn}$ & $\mathrm{Fe}$ & $\mathrm{Ni}$ & $\mathrm{Cu}$ \\
\hline & & & & & & \\
Welded & $4.78 \mathrm{E}+02$ & $>\mathrm{DL}$ & $2.41 \mathrm{E}+02$ & $1.04 \mathrm{E}+04$ & $1.93 \mathrm{E}+03$ & $5.27 \mathrm{E}+03$ \\
Bent \#1 & $4.20 \mathrm{E}+02$ & & $1.11 \mathrm{E}+02$ & $2.50 \mathrm{E}+03$ & $3.50 \mathrm{E}+02$ & $1.44 \mathrm{E}+03$ \\
Bent \#2 & $5.55 \mathrm{E}+02$ & & $7.89 \mathrm{E}+01$ & $1.95 \mathrm{E}+03$ & $4.01 \mathrm{E}+02$ & $1.68 \mathrm{E}+03$ \\
EDM \#1 & $2.02 \mathrm{E}+02$ & & $2.21 \mathrm{E}+02$ & $3.24 \mathrm{E}+03$ & $4.06 \mathrm{E}+02$ & $1.71 \mathrm{E}+03$ \\
EDM \#2 & $1.97 \mathrm{E}+02$ & & N/A & N/A & $9.30 \mathrm{E}+01$ & $2.38 \mathrm{E}+02$ \\
Machined & $4.04 \mathrm{E}+02$ & & $1.83 \mathrm{E}+01$ & $8.83 \mathrm{E}+02$ & $1.43 \mathrm{E}+02$ & $3.82 \mathrm{E}+02$ \\
EDM4 & $9.84 \mathrm{E}+02$ & & $1.51 \mathrm{E}+02$ & $3.68 \mathrm{E}+03$ & $5.15 \mathrm{E}+01$ & N/A \\
EDM6 & N/A & & & $1.81 \mathrm{E}+03$ & N/A & $4.24 \mathrm{E}+02$ \\
\hline
\end{tabular}

\subsection{Material characterization}

The FE-SEM secondary electron images of the as-polished and etched SS-347 samples are shown in Figure 19. SEM micrographs show bright small precipitates (see Figures 19a and $19 \mathrm{~b}$ ) in the austenitic matrix. Figure 19b shows cavities (white arrows) with similar morphology as the precipitates that were not seen in the as-polished specimen. Figure 19b shows cavities at the matrix/precipitate interface. Figures $19 \mathrm{~b}$ shows that the matrix around the precipitates corrodes. The amount of banding of the precipitates observed in Figure 19a and 19b in this type of steel can be associated with carbide formation.

Ten EDS spot analyses were carried out in the austenitic matrix, and three in the precipitates. Figure 20 is a high-magnification FE-SEM image of the etched sample, including the spot analyses on the precipitate. Table 8 presents the EDS spot analyses results in wt \%. Values for the matrix are averages of the 10 different spot EDS analyses, whereas spots 1, 2, and 3 in the precipitates are direct values. These results suggest that the niobium-rich hard phases formed in an austenitic matrix during fabrication of the SS. 


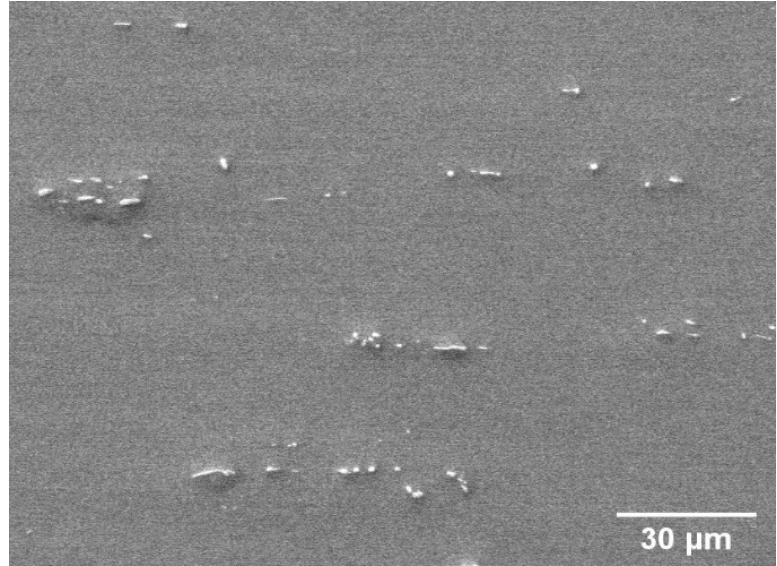

(a)

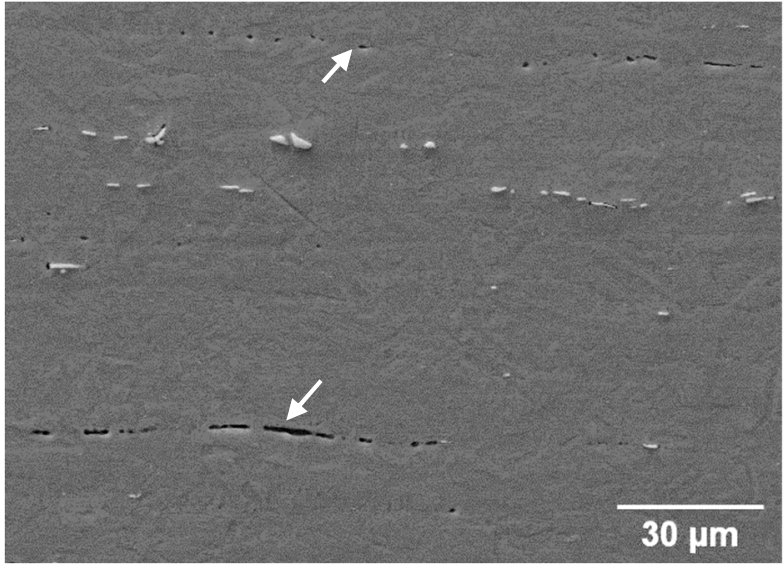

(b)

FIGURE 19 SS-347 FE-SEM secondary electron images (a) polished and (b) etched. White arrows indicate voids or cavities on etched samples.

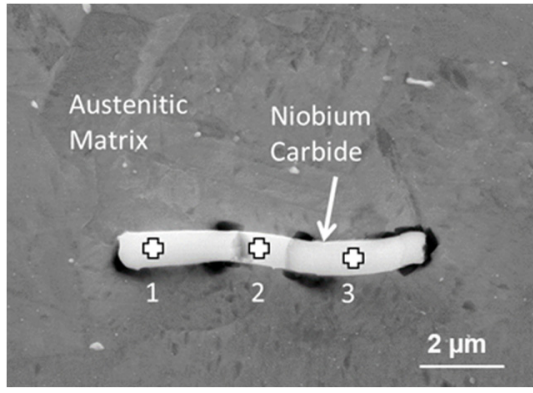

FIGURE 20 FE-SEM in secondary electron mode of SS-347 etched surface. Numbers indicate EDS spot analyses on niobium carbide.

TABLE 8 EDS spot analysis (wt \%)

\begin{tabular}{cccccc}
\hline Spot & $\mathrm{Cr}$ & $\mathrm{Mn}$ & $\mathrm{Fe}$ & $\mathrm{Ni}$ & $\mathrm{Nb}$ \\
\hline & & & & & \\
Matrix & $17.91 \pm 0.26$ & $1.32 \pm 0.07$ & $70.18 \pm 0.47$ & $9.04 \pm 0.30$ & - \\
1 & 9.94 & 0.63 & 31.12 & 3.33 & 54.62 \\
2 & 10.49 & 0.62 & 32.57 & 3.44 & 52.14 \\
3 & 11.46 & 0.88 & 40.3 & 5.03 & 42.14 \\
\hline
\end{tabular}


Figure 21 shows the EDS mapping analysis conducted in the same FE-SEM image as in Figure 20. Note the lack of $\mathrm{Fe}, \mathrm{Cr}, \mathrm{Ni}$, and $\mathrm{Mn}$ in the hard phase, but the richness of $\mathrm{Nb}$. Electron backscattered diffraction analysis (not shown here) has confirmed that the secondary hard phase is niobium carbide $(\mathrm{NbC})$.
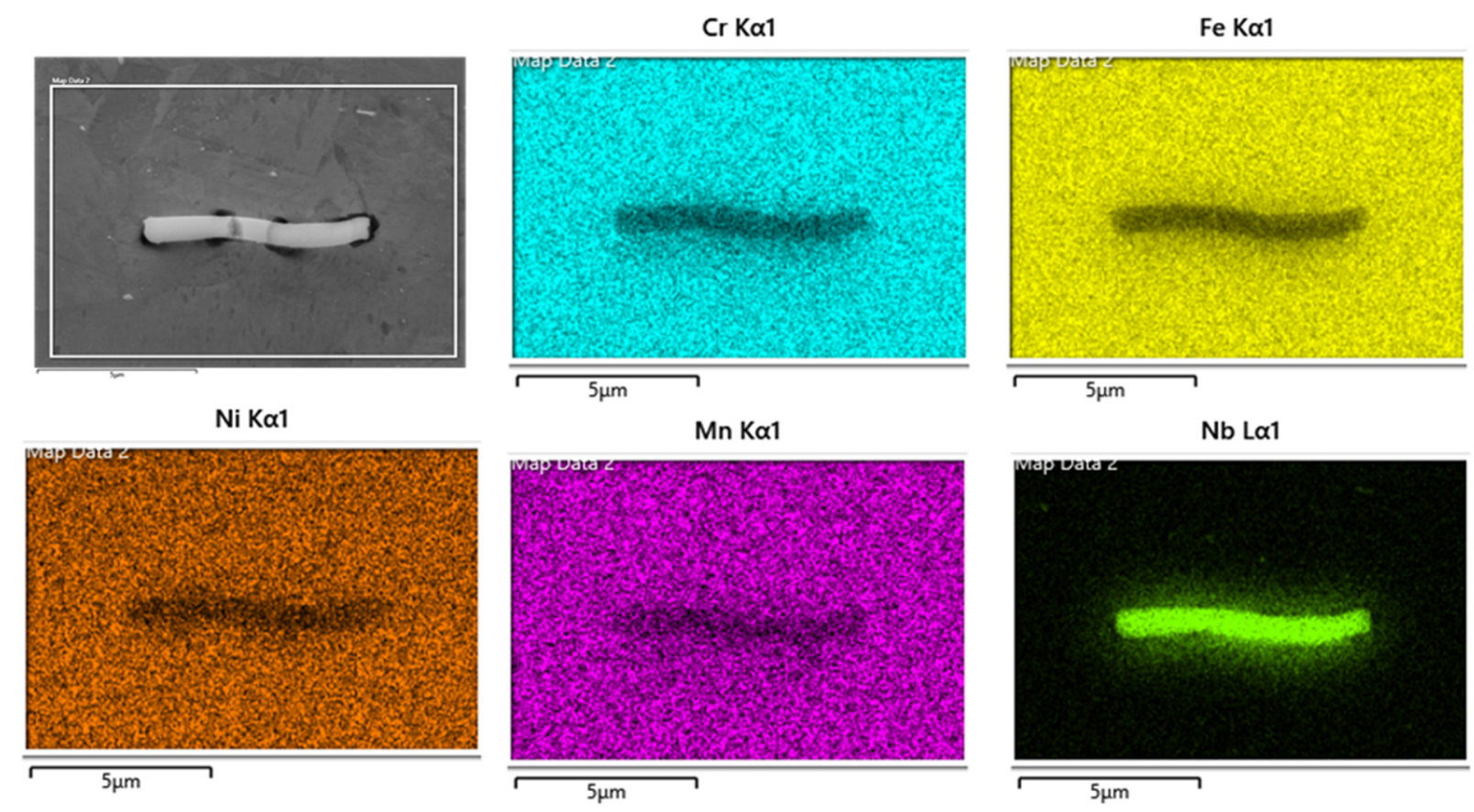

FIGURE 21 EDS mapping analysis of SS-347

Figure 22 is an EDS line scan over a precipitate (bright phase) and covering the austenitic matrix showing no evidence of depletion of $\mathrm{Cr}$ in the austenite in the vicinities of the precipitate. 


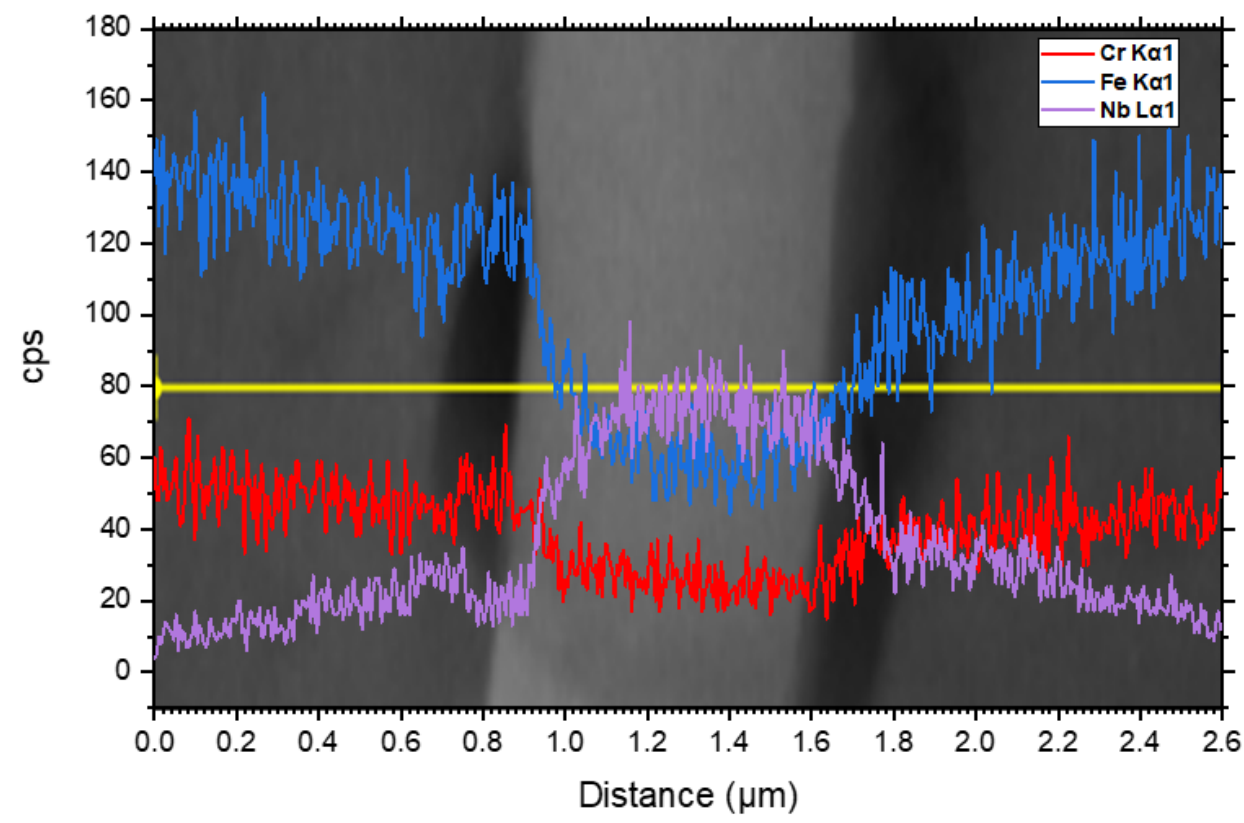

FIGURE 22 EDS line scan analysis covering the matrix (dark phase) and the precipitate (bright phase)

\subsection{Electrochemical corrosion tests}

\subsubsection{Open-circuit potential measurements in $\mathrm{pH}=1 \mathrm{H}_{2} \mathrm{SO}_{4}$ at $\mathrm{RT}$}

OCP measurements were conducted with SS-347 for a period of 28 days in $\mathrm{pH}=1 \mathrm{H}_{2} \mathrm{SO}_{4}$ at RT, as shown in Figure 23. Electrochemical impedance spectroscopy (EIS) was conducted daily during the OCP measurements to monitor the surface electrical properties.

The OCP showed three different segments, highlighted by the colors black (Segment 1), red (Segment 2), and blue (Segment 3). The OCP in Segment 1 stabilized after 8 days at about 0.06 VSCE. However, significant potential drops were observed at 15 and 22 days, which could be attributed to the preferential corrosion of the matrix around the precipitates ( $\mathrm{Nb}$ carbides). As a result, the carbides may have dropped out of the surface, creating bare (unprotected) surface, leading to more corrosion on the surface. The OCP subsequently stabilized at about -0.01 VSCE in Segment 3 after 28 days. Arrows over the plot indicate time and OCP at which a representative EIS curve of each of the segments was selected for analyses. 


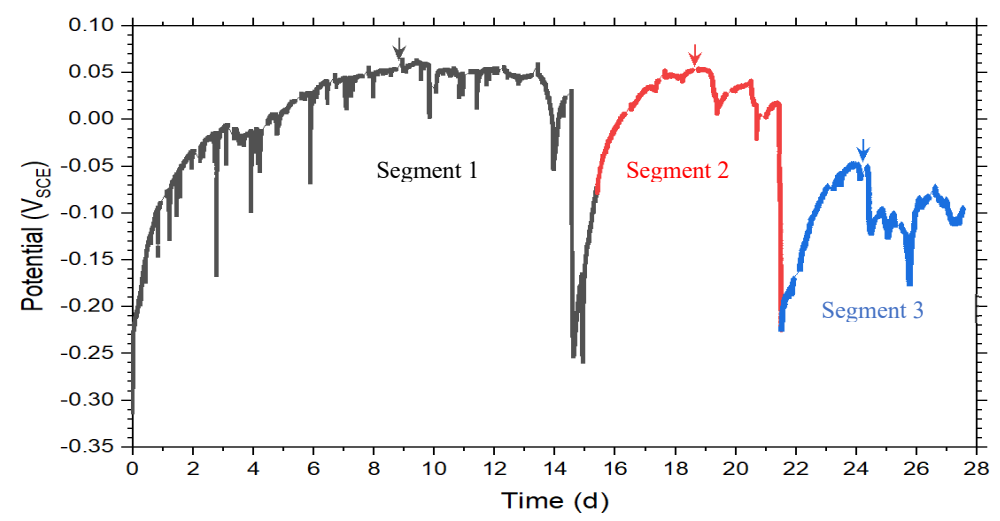

FIGURE 23 Long-term exposure OCP measurements of SS-347 in $\mathrm{pH}=1 \mathrm{H}_{2} \mathrm{SO}_{4}$ at RT. Arrows indicate the potential and time at which the EIS took place.

EIS measurements from each segment are shown in Figure 24. The Bode magnitude plot shown in Figure 24a indicates the surface impedance dropped over time, which is consistent with the decrease in the OCP values. The Bode phase plot in Figure 24b shows a decrease in the phase angles between Segments 2 and 3, which indicates a less corrosion-resistant surface. The Nyquist plot in Figure 24c shows the surface becoming less capacitive over time. The Nyquist curve for Segment 3 shows the typical diffusion behavior (Warburg effect), which confirms new bare surfaces were exposed after carbide precipitates dropped out due to localized corrosion of the matrix/carbide phase boundary.

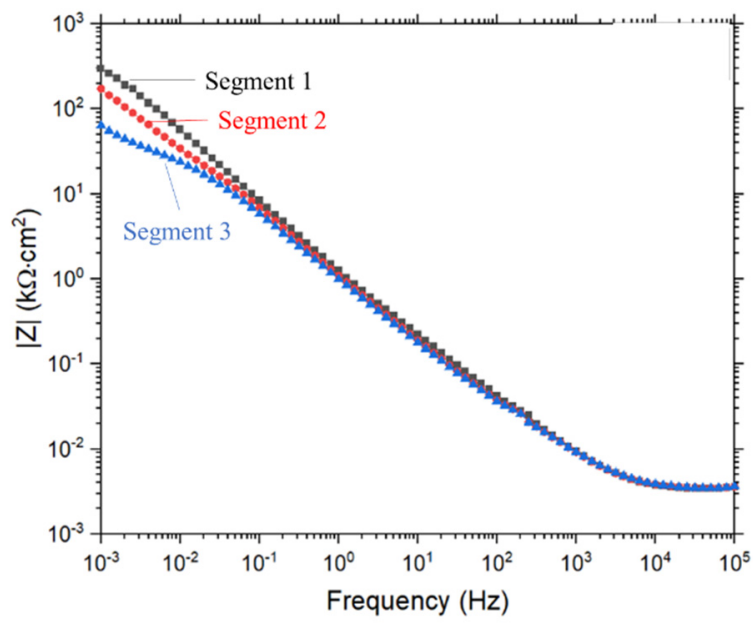

(a)

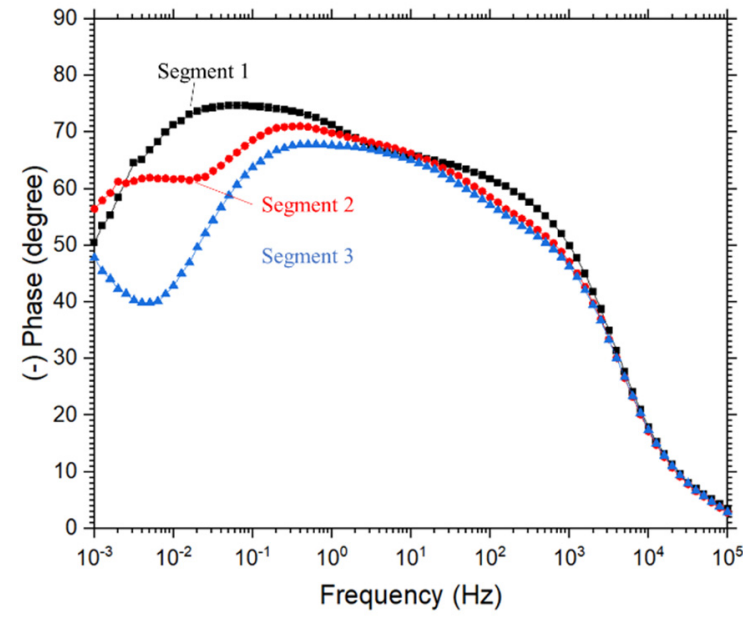

(b) 


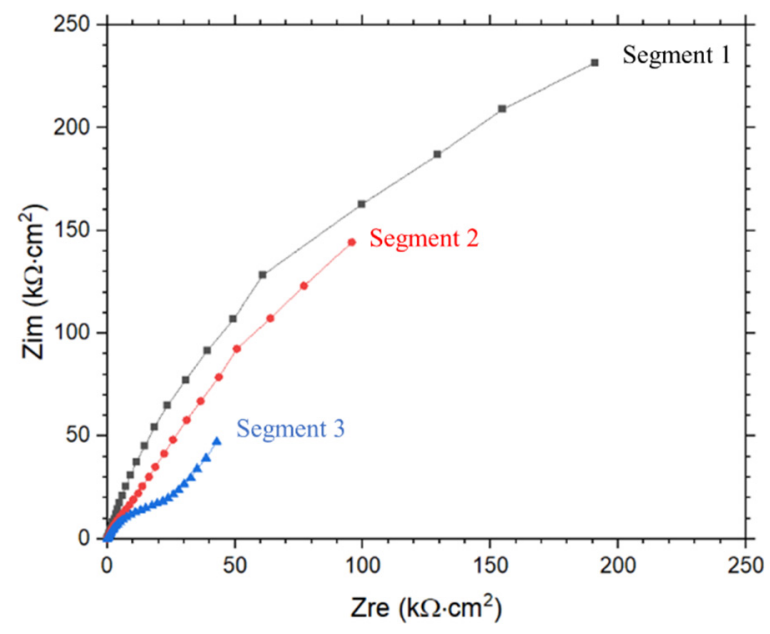

(c)

FIGURE 24 EIS plots of three sections of long-term OCP of SS-347 in $\mathrm{pH}=1 \mathrm{H}_{2} \mathrm{SO}_{4}$ : (a) Bode phase angle, (b) Bode magnitude, (c) Nyquist

\subsubsection{Potentiodynamic scans}

Potentiodynamic (PD) scans of the as-received, nonirradiated SS-347 samples conducted in $\mathrm{H}_{2} \mathrm{SO}_{4}$ and $\mathrm{UO}_{2} \mathrm{SO}_{4}$ at RT are shown in Figure 25FIGURE. The PD scan in $\mathrm{H}_{2} \mathrm{SO}_{4}$ shows an active corrosion region above ECORR up to about $-0.1 \mathrm{~V}_{\mathrm{SCE}}$, followed by a passive region up to about $0.84 \mathrm{~V}_{\mathrm{SCE}}$. The current density remained nearly constant until $\sim 0.4 \mathrm{~V}_{\text {SCE }}$ and it increased gradually until $0.84 \mathrm{VSCE}$. Between 0.84 and $1.07 \mathrm{VSCE}$ the currents increased dramatically by 3 orders of magnitude. A pseudopassive region was observed at 1.07-1.4 VSCE. Above 1.4 VSCE the currents increased as a result of oxygen evolution. The PD scan with SS-347 in $\mathrm{UO}_{2} \mathrm{SO}_{4}$ shows similar corrosion behavior. However, the ECORR shifted 0.22 VSCE upward (more cathodic) and the corrosion currents increased about 5-6 times in the passive region. The corrosion behavior in the transpassive region was similar to that observed in the PD scan in $\mathrm{H}_{2} \mathrm{SO}_{4}$ solution. 


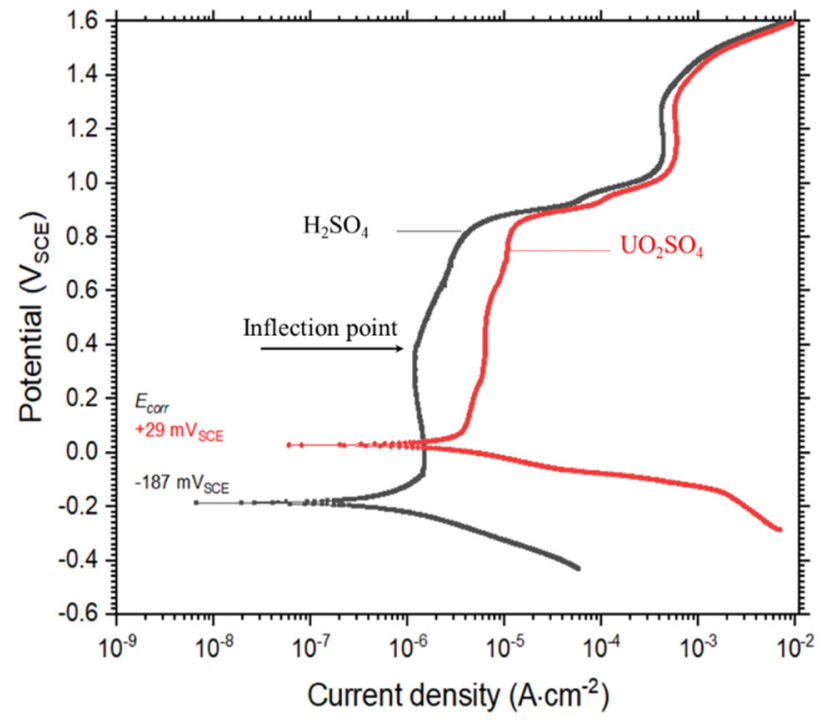

FIGURE 25 PD scans with SS-347 in $\mathrm{pH}=1 \mathrm{H}_{2} \mathrm{SO}_{4}$ and $\mathrm{UO}_{2} \mathrm{SO}_{4}$ solution at $\mathrm{RT}$

PD scans comparing corrosion behaviors of SS-347 at RT and $80^{\circ} \mathrm{C}$ in $\mathrm{H}_{2} \mathrm{SO}_{4}$ and $\mathrm{UO}_{2} \mathrm{SO}_{4}$ solutions are shown in Figure 26. Figure 26a shows ECORR in the PD scan at $80^{\circ} \mathrm{C}$ increased (became more cathodic) by 0.18 VSCE compared with ECORR at RT. Although the currents measured in the passive regions are similar, the transpassive potential was measured at about $0.74 \mathrm{~V}_{\text {SCE }}$ in the PD scan at $80^{\circ} \mathrm{C}$, which is $0.1 \mathrm{VSCE}$ lower than the value measured at RT. Figure 26b shows the PDs of as-received SS-347 in $\mathrm{UO}_{2} \mathrm{SO}_{4}$ at RT and $80^{\circ} \mathrm{C}$; it reveals similar current densities and a slight increase in ECORR of about $0.05 \mathrm{~V}_{\mathrm{SCE}}$ at $80^{\circ} \mathrm{C}$. Transpassive behavior was observed at $0.73 \mathrm{VSCE}$ at $80^{\circ} \mathrm{C}$. This suggests that the higher temperature reduces the passive voltage range in both electrolytes.

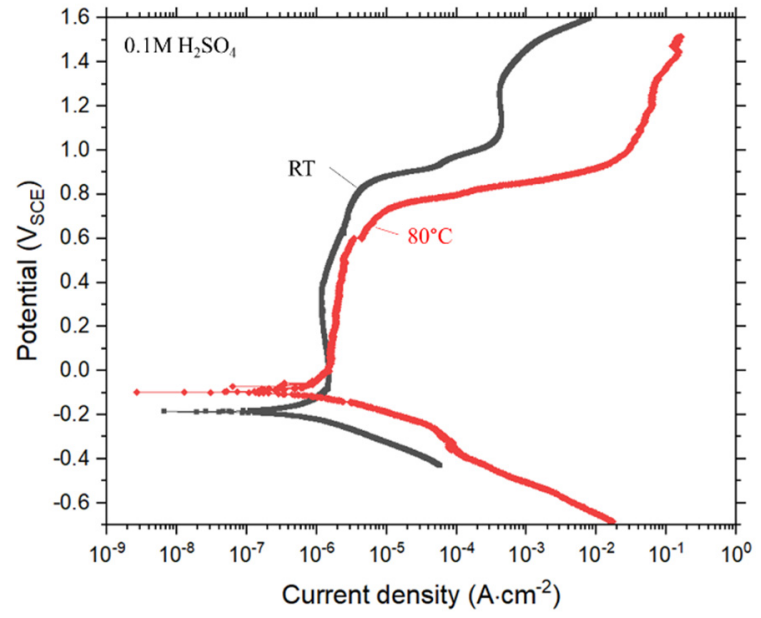

(a)

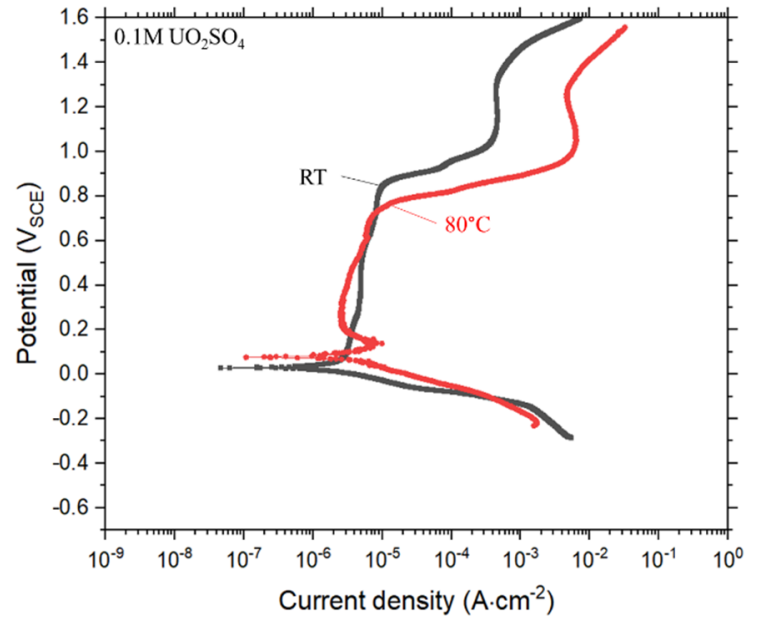

(b)

FIGURE $26 \mathrm{PD}$ scans at $\mathrm{RT}$ and $80^{\circ} \mathrm{C}$ of SS-347 in (a) $\mathrm{pH}=1 \mathrm{M} \mathrm{H}_{2} \mathrm{SO}_{4}$ and (b) $\mathrm{UO}_{2} \mathrm{SO}_{4}$ solutions 
Figure 27 shows FE-SEM images of the SS-347 sample after the PD scans in $\mathrm{H}_{2} \mathrm{SO}_{4}$ and $\mathrm{UO}_{2} \mathrm{SO}_{4}$ at $25^{\circ} \mathrm{C}$ and $80^{\circ} \mathrm{C}$. Figure 27 a shows minor pitting and carbide corrosion on the surface after a $\mathrm{PD}$ scan at $25^{\circ} \mathrm{C}$ in $\mathrm{H}_{2} \mathrm{SO}_{4}$ solution. However, $\mathrm{UO}_{2} \mathrm{SO}_{4}$ solution at the same temperature shows a brittle oxide layer on the surface but no evidence of pitting or carbide corrosion (Figure 27c). Figure 27b shows severe corrosion damage with extensive pitting after a PD scan at $80^{\circ} \mathrm{C}$ in $\mathrm{H}_{2} \mathrm{SO}_{4}$ solution. Figure $27 \mathrm{~d}$ also shows uniform, but less aggressive, corrosion and pitting on the surface after a $\mathrm{PD}$ scan at $80^{\circ} \mathrm{C}$ in $\mathrm{UO}_{2} \mathrm{SO}_{4}$ solution. This suggests the passive oxide film is not protective at higher temperatures, which is also apparent from the reduction in passive range (see Figure 26) in both solutions.

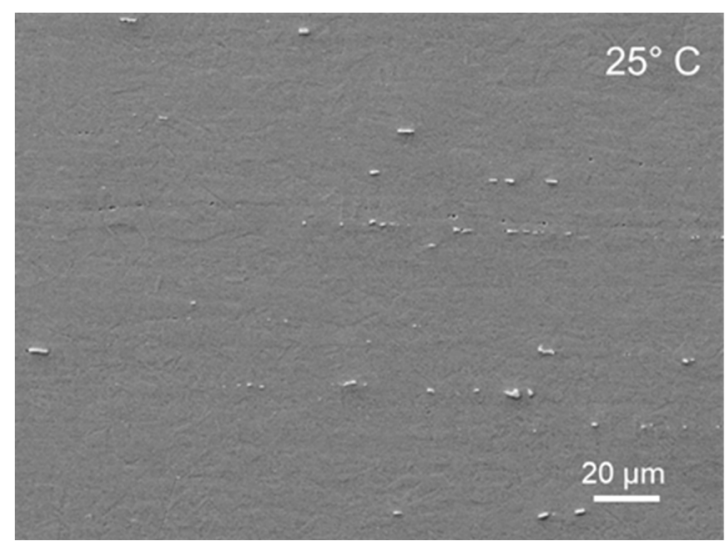

(a)

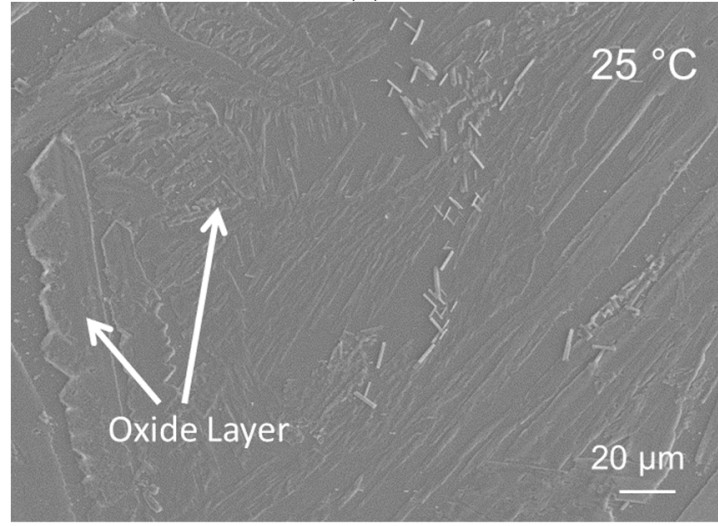

(c)

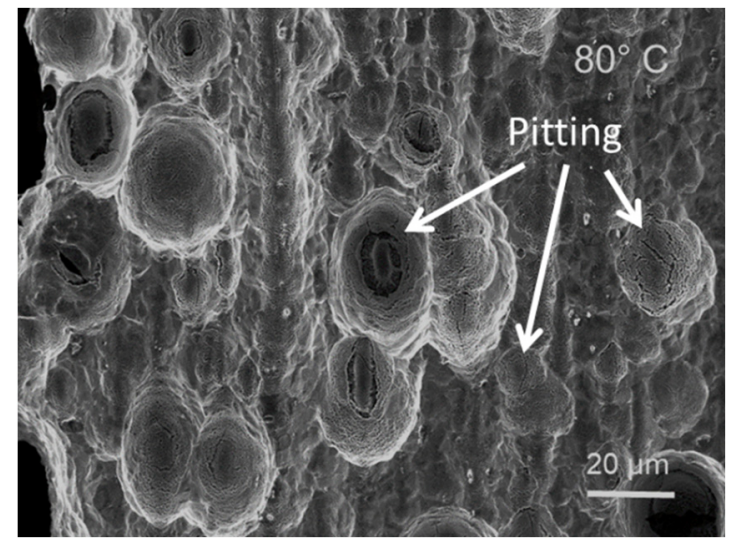

(b)

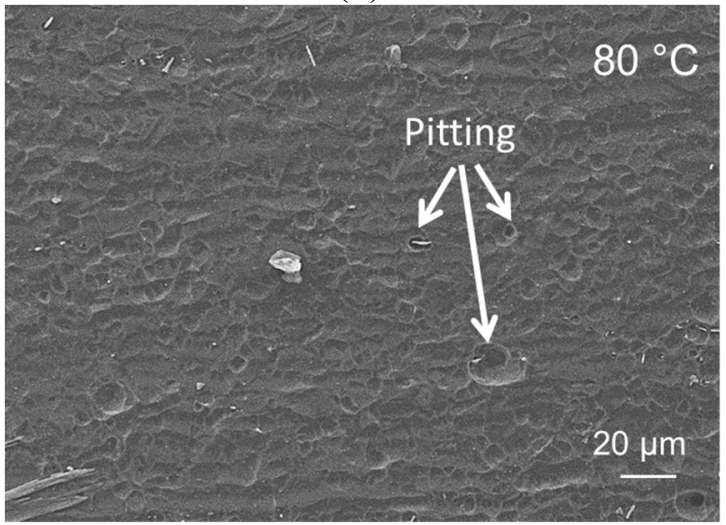

(d)

FIGURE 27 SEM micrographs of SS-347 electrode surfaces after PD scans in $\mathrm{pH}=1 \mathrm{H}_{2} \mathrm{SO}_{4}$ solution at (a) $\mathrm{RT}$ and (b) $80^{\circ} \mathrm{C}$, and in $\mathrm{UO}_{2} \mathrm{SO}_{4}$ solution at (c) $\mathrm{RT}$ and (d) $80^{\circ} \mathrm{C}$

Figure 28 shows the PD scans of as-received SS-347 flat and bent samples in $\mathrm{pH}=1 \mathrm{H}_{2} \mathrm{SO}_{4}$ at $\mathrm{RT}$. There is noticeable increase in current density within the passive region in the bent specimen, but it has the same current density than the as-received samples in the transpassive regions for both electrolytes. The EcorR values at $\mathrm{RT}$ in the $\mathrm{pH}=1 \mathrm{H}_{2} \mathrm{SO}_{4}$ for both samples are the same. This suggests that the current density increase is only due to residual stresses developed in the bent sample, and the low-voltage transpassive transition is only due to the temperature effect on the stability of the passive film. 


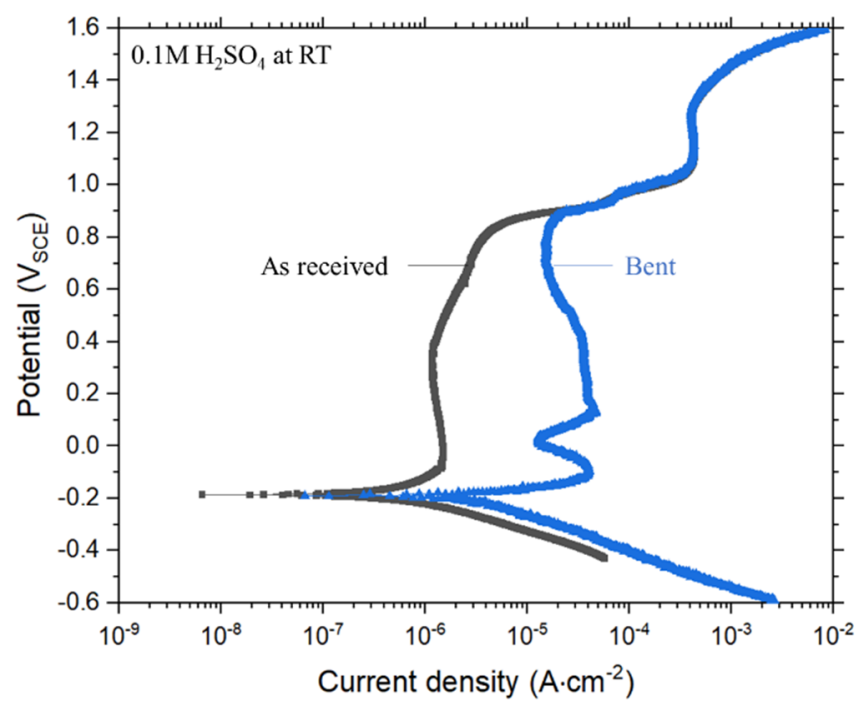

FIGURE 28 PD scans of SS-347 as-received and bent specimens in $\mathrm{pH}=1 \mathrm{H}_{2} \mathrm{SO}_{4}$ at $\mathrm{RT}$

Figure 29 is the SEM image of the electrode surface of the bent sample after the PD scan in $\mathrm{pH}=1 \mathrm{H}_{2} \mathrm{SO}_{4}$ at $\mathrm{RT}$. It exhibits intergranular corrosion, which was not observed in the asreceived working electrode, suggesting that the increase in corrosion density in the PD scan is due to deformation of the metal. The accumulation of dislocations due to bending increased the localized energy at the grain boundaries, making them more susceptible to corrosion. The changes in current density in the transpassive region were the same for both specimens.

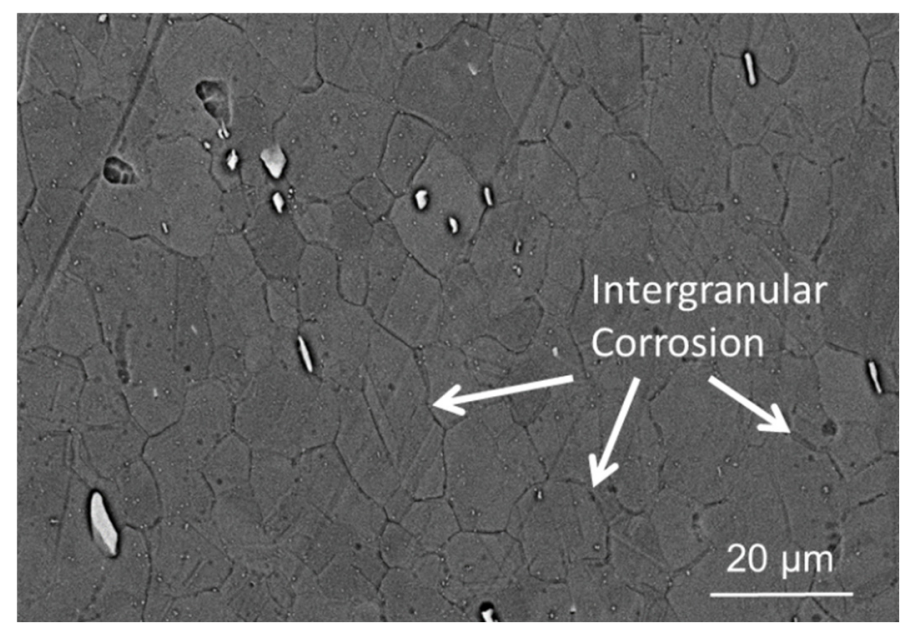

FIGURE 29 SS-347 bent specimen after PD scan at $\mathrm{RT}$ in $\mathrm{pH}=1 \mathrm{H}_{2} \mathrm{SO}_{4}$ solution 
Figure 30 shows the PD scans of as-received (flat) and bent SS-347 samples in $\mathrm{pH}=1 \mathrm{UO}_{2} \mathrm{SO}_{4}$ at $80^{\circ} \mathrm{C}$. The $\mathrm{PD}$ scan for bent sample shows again a noticeable increase in current density within the passive region, and an ECORR that is more anodic than the as-received sample. The transpassive potentials observed in the PD scans and the current densities of the asreceived (flat) and bent samples are the same. Similar to the PD scan at RT, the deformation of the steel matrix contributed to the lower corrosion resistance of the bent sample. This suggests that the high current densities could be due to the residual stresses present in the bent sample.

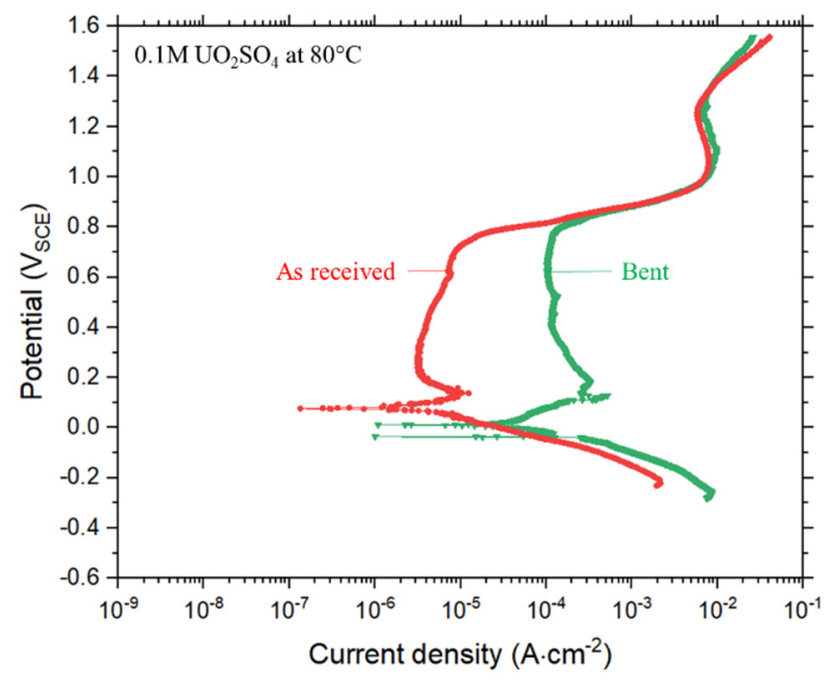

FIGURE 30 PD scans of SS-347 as-received and bent specimens in $\mathrm{pH}=1 \mathrm{UO}_{2} \mathrm{SO}_{4}(200 \mathrm{~g} / \mathrm{L})$ at $80^{\circ} \mathrm{C}$

Figure 31 is the SEM image of the bent sample after the $\mathrm{PD}$ scan in $\mathrm{pH}=1 \mathrm{UO}_{2} \mathrm{SO}_{4}$ $(200 \mathrm{~g} / \mathrm{L})$ at $80^{\circ} \mathrm{C}$. The surface shows pitting with minor intergranular corrosion and a thick oxide brittle layer, which may be due to tensile deformation of the microstructure. As discussed above, the accumulation of dislocations due to bending increases the localized energy at the grain boundaries, making them more susceptible to corrosion. 


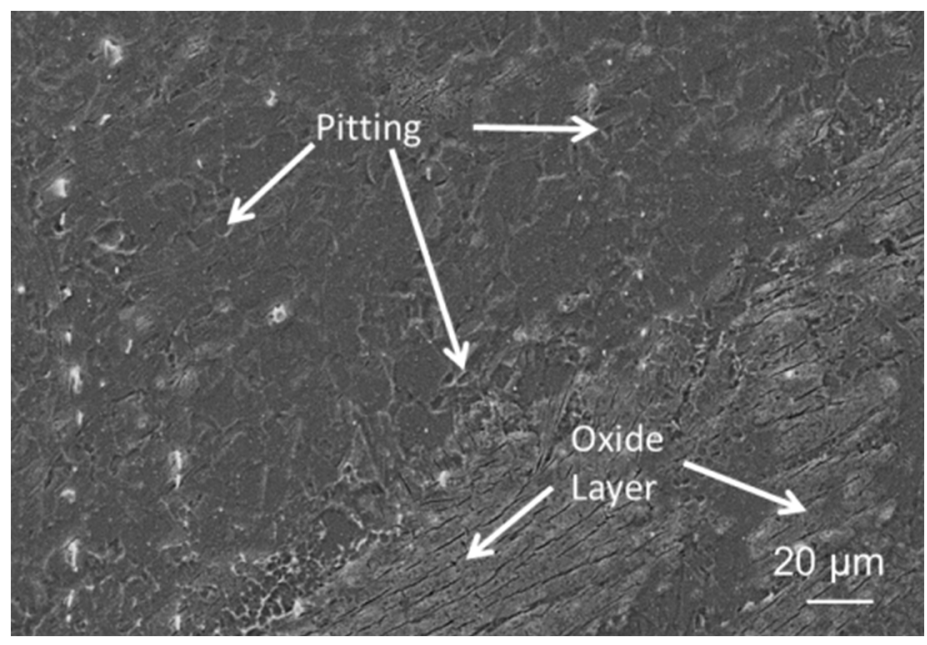

FIGURE 31 SEM after PD Scan with bent sample in $\mathrm{pH}=1 \mathrm{UO}_{2} \mathrm{SO}_{4}(200 \mathrm{~g} / \mathrm{L})$ at $80^{\circ} \mathrm{C}$

Figure 32 shows the PD scans of as-received (flat), bent, and welded SS-347 samples in $0.1 \mathrm{M} \mathrm{UO}_{2} \mathrm{SO}_{4}$ at $80^{\circ} \mathrm{C}$. The PD scan for welded coupon shows the ECORR was similar to that of the as-received sample. However, the welded sample did not show a well-defined passive region and the current densities increased with potential. This is most likely due to the residual stresses generated due to welding. It is important to note that the current densities measured at higher voltages $(>0.7 \mathrm{VSCE})$ for the welded sample were similar to the bent sample. However, the transpassive potentials observed in the PD scans for all three samples were the same.

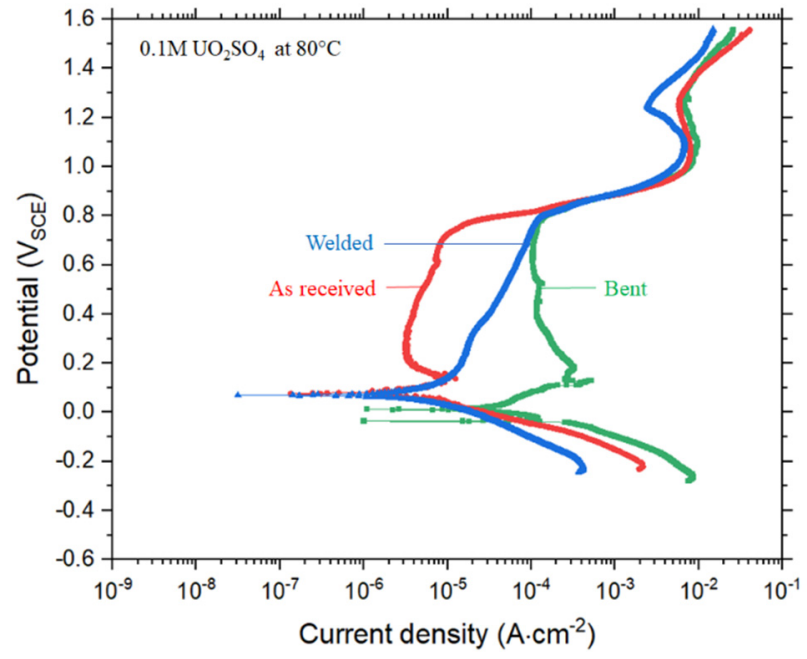

FIGURE 32 PD scans of as-received, bent, and welded SS-347 samples in $\mathrm{pH}=1 \mathrm{UO}_{2} \mathrm{SO}_{4}$ $(200 \mathrm{~g} / \mathrm{L})$ at $80^{\circ} \mathrm{C}$ 


\subsubsection{Potentiostatic studies at RT}

The PS tests were conducted at various applied voltages that represent imposed redox conditions that could be generated due to changing environmental conditions (redox, chemistry, $\mathrm{pH}, \mathrm{T}$ ) in the solution during Mo-99 production. Long-term PS tests were conducted at 0.5 and $0.8 \mathrm{VSCE}$ in the passive region, and at $1.0 \mathrm{VSCE}$ in the transpassive region, at RT for 10 days in $\mathrm{pH}=1 \mathrm{H}_{2} \mathrm{SO}_{4}$ and $\mathrm{pH}=1 \mathrm{UO}_{2} \mathrm{SO}_{4}(200 \mathrm{~g} / \mathrm{L})$ solutions.

The current densities during the PS tests in the passive region ( 0.5 and $0.8 \mathrm{VSCE}$ ) show an initial drop and seem to stabilize at a lower value $\left(<1 \mu \mathrm{A} / \mathrm{cm}^{2}\right)$ in both solutions. Figure 33 shows significant differences in current densities between PS tests conducted at 0.5 and 0.8 VSCE, which is expected and can be attributed to the efficiency and type of oxide films (Cr-based or Ni-based) formed at each voltage.

Figure 33a shows PS currents with considerable fluctuations and substantial current spikes at 0.5 and $0.8 \mathrm{VSCE}$. These current spikes were most likely associated with pitting followed by detachment of $\mathrm{NbC}$ precipitates. However, SEM analysis of the electrode surfaces after PS tests showed no signs of visible corrosion. These current spikes or fluctuations were not observed in PS currents measured at the same voltages in $\mathrm{UO}_{2} \mathrm{SO}_{4}$ solution (see Figure 33b). This suggests that the passive film developed was metastable in $\mathrm{H}_{2} \mathrm{SO}_{4}$, which also agrees with OCP measurements (see Figure 23).

The current densities measured at each voltage were slightly lower in $\mathrm{pH}=1 \mathrm{UO}_{2} \mathrm{SO}_{4}$ solution compared with $\mathrm{pH}=1 \mathrm{H}_{2} \mathrm{SO}_{4}$ solution at 10 days. The passive films formed in $\mathrm{pH}=1 \mathrm{UO}_{2} \mathrm{SO}_{4}$ solution were relatively more stable. High current densities were measured at 1.0 VSCE that increased slightly in both solutions. The currents stabilized over 10 days to $0.5-1 \mathrm{~mA} \cdot \mathrm{cm}^{-2}$, indicative of active corrosion. This also suggests that the oxide film that formed at $1.0 \mathrm{VSCE}$ was not protective, making the surface susceptible to corrosion.

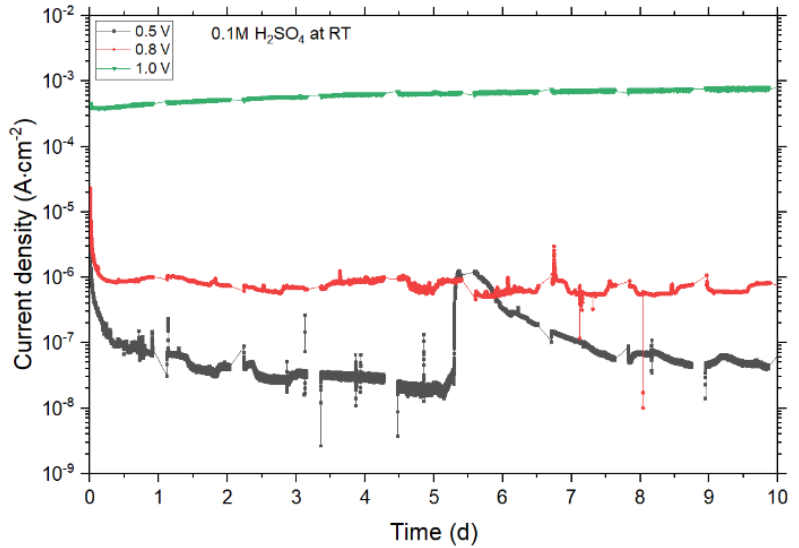

(a)

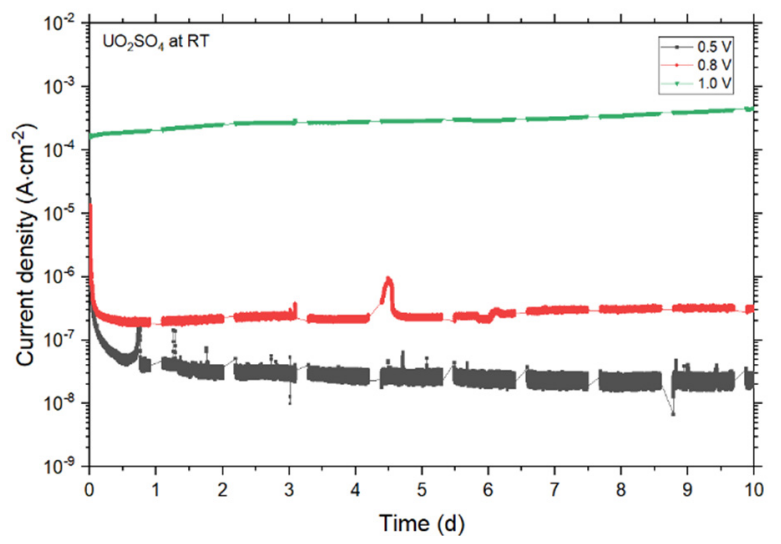

(b)

FIGURE 33 PS measurements at different redox potentials of SS-347 at RT in (a) $0.1 \mathrm{M} \mathrm{H}_{2} \mathrm{SO}_{4}$ and (b) $0.1 \mathrm{M} \mathrm{UO} \mathrm{SO}_{4}$ 
EIS measurements from each of the as-received SS-347 samples following PS tests in the two electrolyte solutions are shown in Figure 34. Figures 34a, 34c, and 34e correspond to the tests conducted in $\mathrm{H}_{2} \mathrm{SO}_{4}$ solution, and Figures $34 \mathrm{~b}, 34 \mathrm{~d}$, and $34 \mathrm{f}$ are for the PS tests in $\mathrm{UO}_{2} \mathrm{SO}_{4}$ solution.

The Bode magnitude plots shown in Figures 34a and 34b indicate the surface impedance dropped as the applied voltage increased. The impedances of the samples tested in the passive regions in $\mathrm{H}_{2} \mathrm{SO}_{4}$ were lower than those tested in $\mathrm{UO}_{2} \mathrm{SO}_{4}$ solution. The Bode magnitude plots for the samples tested at the applied voltage of $1.0 \mathrm{VSCE}$ (transpassive region) show the same values as in Figures 34e and 34f.

The Bode phase angle plots in Figures 34c and 34d also indicate a decrease in the phase angles with increasing applied voltages, representing less corrosion-resistant surfaces, which is expected with the higher applied voltages.

Nyquist plots in Figures 34e and 34f show that the surface became less capacitive with higher applied voltages, but the samples exposed to the $\mathrm{UO}_{2} \mathrm{SO}_{4}$ had better corrosion resistance.

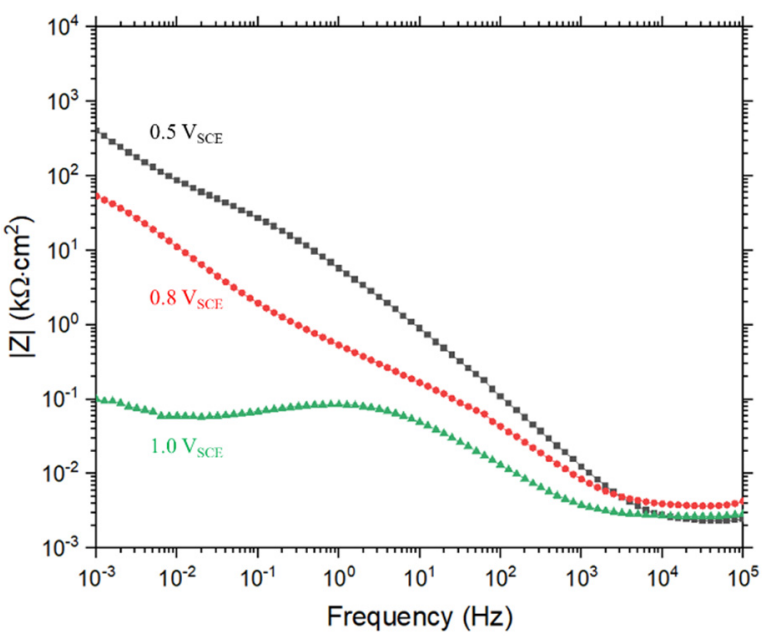

(a)

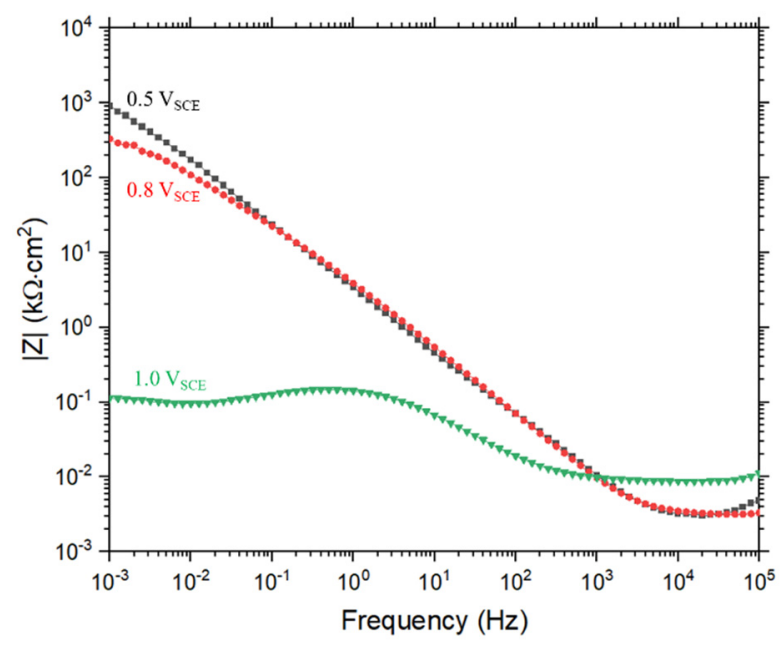

(b) 


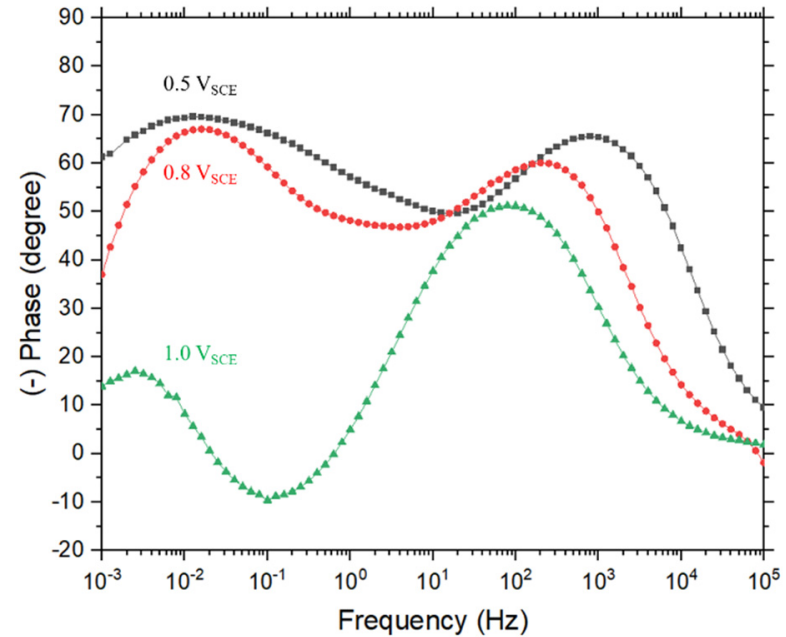

(c)

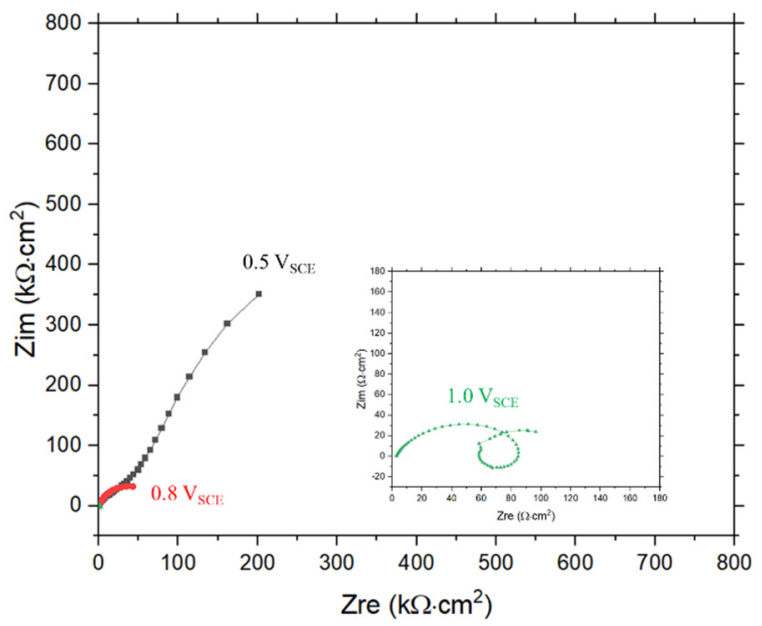

(e)

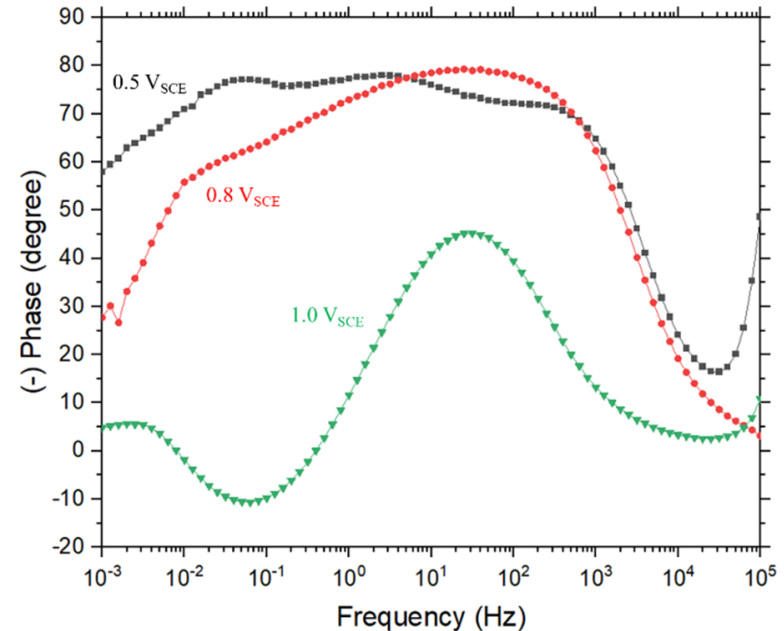

(d)

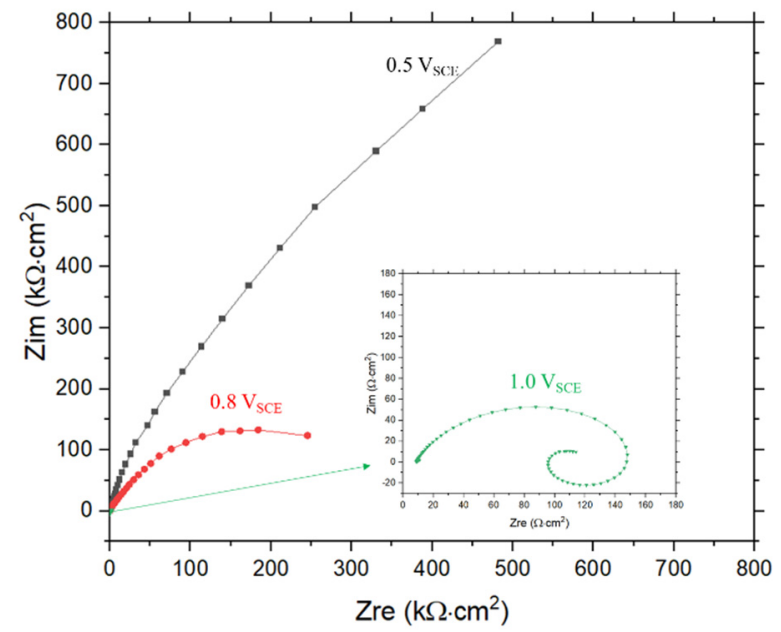

(f)

FIGURE 34 EIS plots at the 10th day of PS measurements of as-received SS-347 in $\mathbf{p H = 1} \mathbf{H}_{2} \mathrm{SO}_{4}$ (a, c, and e) and $\mathrm{pH}=1 \mathrm{UO}_{2} \mathrm{SO}_{4}(\mathrm{~b}, \mathrm{~d}$, and $\mathrm{f}$ ). Bode phase angle (a and b), Bode magnitude (c and d), and Nyquist (e and f).

\subsubsection{Potentiostatic tests with as-received $\mathrm{SS}-347$ in $\mathrm{H}_{2} \mathrm{SO}_{4}$ solution at $\mathrm{RT}$ and $80^{\circ} \mathrm{C}$}

PS corrosion tests were conducted with flat as-received SS-347 at RT and $80^{\circ} \mathrm{C}$ and bent as-received (Bent $\# 0$ ) at RT samples in $\mathrm{pH}=1 \mathrm{H}_{2} \mathrm{SO}_{4}$ solution. Figure 35 shows current profiles measured during the PS tests $\left(0.8 \mathrm{~V}_{\mathrm{SCE}}\right)$ conducted under the redox conditions expected to be generated during Mo-99 production.

Corrosion current densities $\left(\sim 10^{-6} \mathrm{~A} / \mathrm{cm}^{2}\right)$ measured in the PS test at RT for flat and bent samples indicate a stable passive surface. The sample surfaces after PS tests at RT did not show visible corrosion. Relatively higher corrosion current densities $\left(1 \times 10^{-5} \mathrm{~A} / \mathrm{cm}^{2}\right)$ were measured in the PS test conducted with flat sample at $80^{\circ} \mathrm{C}$; these current densities were about an order of 
magnitude higher those measured at RT, which indicates accelerated corrosion and high corrosion rates.

Figure 36 shows FE-SEM images of the SS-347 surface after the PS test at $80^{\circ} \mathrm{C}$. Figure 36a is a low- magnification image of the electrode surface after the PS test. Figure 36b is a high-magnification image of the surface showing intergranular corrosion between austenite grains and at the interface of $\mathrm{NbC}$ precipitates (bright white) and matrix. The surface also had localized pitting corrosion on the austenitic grains.

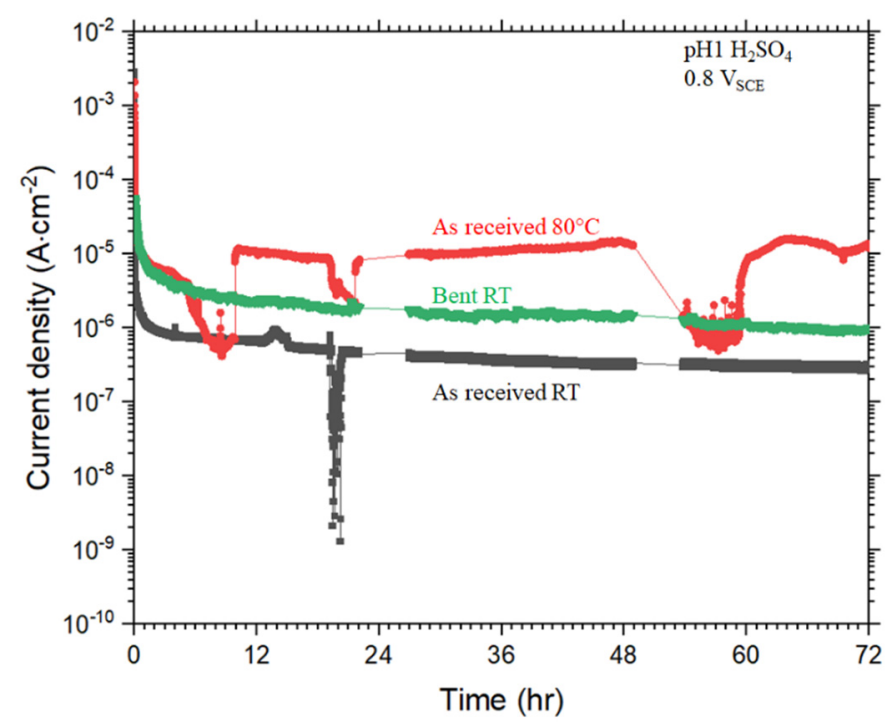

FIGURE 35 PS measurements at RT and $80^{\circ} \mathrm{C}$ of SS-347 in $\mathrm{pH}=1 \mathrm{H}_{2} \mathrm{SO}_{4}$ at $0.8 \mathrm{~V}_{\mathrm{SCE}}$

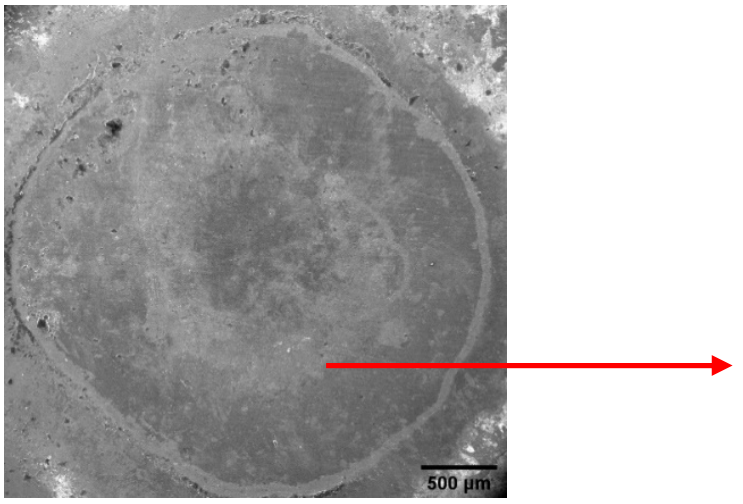

(a)

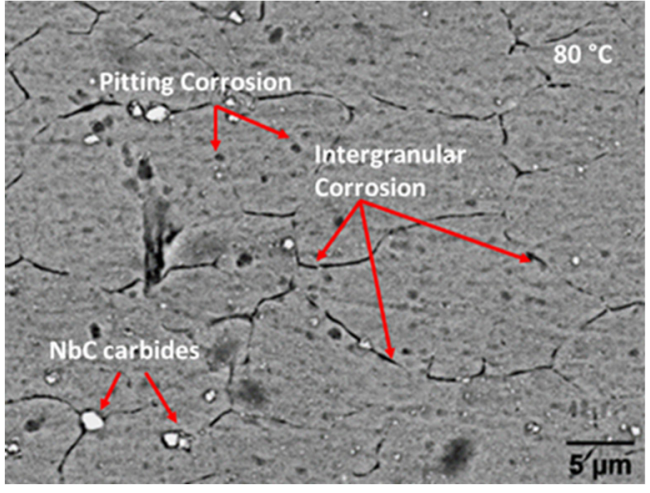

(b)

FIGURE 36 SEM images of the as-received SS-347 surface after PS measurement in $\mathrm{pH}=1 \mathrm{H}_{2} \mathrm{SO}_{4}$ at $80^{\circ} \mathrm{C}$ : (a) low magnification (b) high magnification 


\subsubsection{Potentiostatic studies with irradiated $\mathrm{SS}-347$ samples in $\mathrm{UO}_{2} \mathrm{SO}_{4}$ solution at $80^{\circ} \mathrm{C}$}

PS tests were conducted with SS-347 to assess the effects of high temperature and irradiation on the corrosion performance. As-received non irradiated SS-347 samples are identified as N-rad. Two N-rad samples, samples with different levels of irradiation, M-rad (mild, EDM \#4) and H-rad (high, EDM \#6), and welded (Welded \#1) were used in the tests. Figure 37 shows the current densities measured at $0.8 \mathrm{VSCE}$ (highly oxidizing redox condition) in $\mathrm{pH}=1 \mathrm{UO}_{2} \mathrm{SO}_{4}(\mathrm{dU}=200 \mathrm{~g} / \mathrm{L})$ solution at $\mathrm{RT}$ and at $80^{\circ} \mathrm{C}$. The current measurements with N-rad samples at $80^{\circ} \mathrm{C}$ were an order of magnitude higher than at RT. At $80^{\circ} \mathrm{C}$, the Welded \#1 sample had the highest current densities followed by the H-rad, M-rad, and N-rad samples.

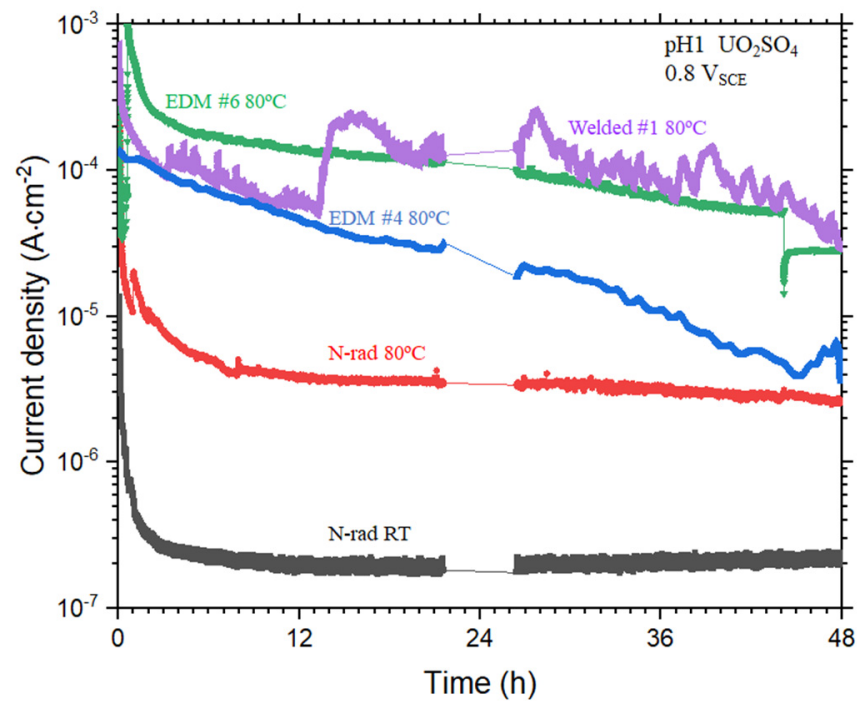

FIGURE 37 PS tests conducted at $0.8 \mathrm{~V}_{\text {SCE }}$ with SS-347 samples: N-rad, M-rad, H-rad, and Welded \#1 at $\mathrm{RT}$ and $80^{\circ} \mathrm{C}$ in $\mathrm{pH}=1 \mathrm{UO}_{2} \mathrm{SO}_{4}$ $(\mathrm{dU}=\mathbf{2 0 0} \mathrm{g} / \mathrm{L})$ solution

Figure 38 is the SEM image of the N-rad, M-rad (EDM \#4), H-rad (EDM \#6), and Welded \#1 samples after PS tests at $0.8 \mathrm{VSCE}$ after $48 \mathrm{~h}$ at $80^{\circ} \mathrm{C}$ in $\mathrm{UO}_{2} \mathrm{SO}_{4}$ solution. A thick and compact oxide layer was observed on the N-rad surface, as shown in Figure 38a. The M-rad sample surface showed localized pitting (Figure 38b, white arrows) and a brittle oxide layer (white circles in Figure 38b). Similar results were found in the H-rad sample but the oxide layers were visually thicker and more brittle (see Figure 38c). Figure 38d shows corrosion in fusion zone of the welded region on the sample surface. 


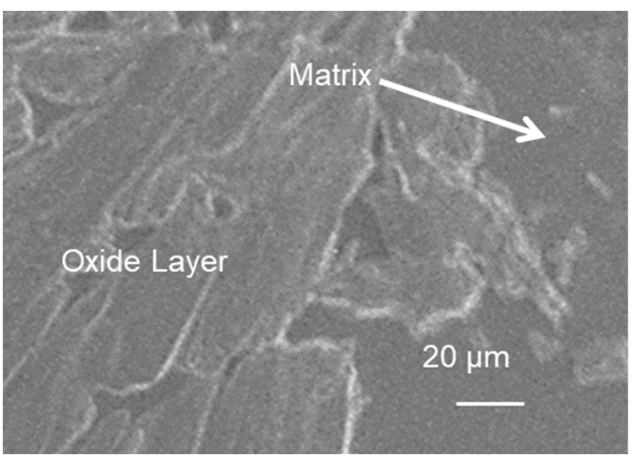

(a)

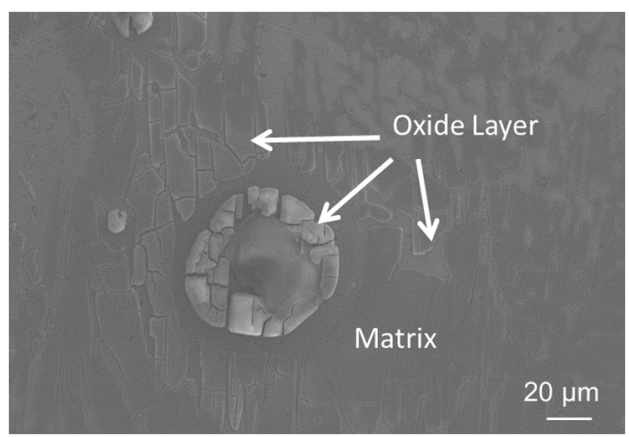

(c)

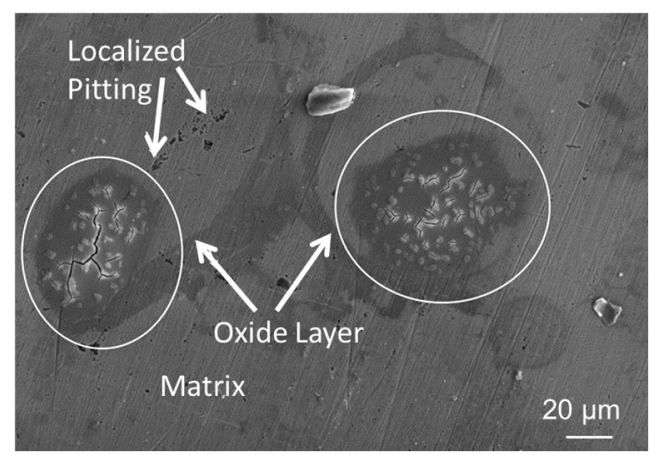

(b)

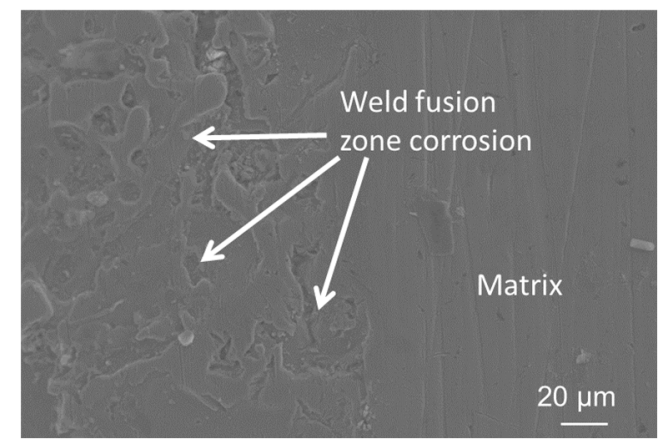

(d)

FIGURE 38 SEM images of (a) N-rad, (b) M-rad, (c) H-rad SS-347, and (d) Welded \#1 samples after PS tests at $80^{\circ} \mathrm{C}$ in $\mathrm{pH}=1 \mathrm{UO}_{2} \mathrm{SO}_{4}(\mathrm{dU}=200 \mathrm{~g} / \mathrm{L})$ solutions

EIS measurements from each of the N-rad, M-rad (EDM \#4), H-rad (EDM \#6), and Welded \#1 samples following PS tests in $\mathrm{UO}_{2} \mathrm{SO}_{4}$ solutions are shown in Figure 39. The Bode magnitude plots shown in Figure 39a indicate the surface impedance dropped from $500 \mathrm{k} \Omega \mathrm{cm}^{2}$ for the N-rad sample at RT to $90 \mathrm{k} \Omega \mathrm{cm}^{2}$ for the N-rad sample at $80^{\circ} \mathrm{C}$, indicating the surface was less corrosion resistant at the elevated temperature. The impedance values also dropped from $90 \mathrm{k} \Omega \mathrm{cm}^{2}$ for N-rad sample at $80^{\circ} \mathrm{C}$ to $2 \mathrm{k} \Omega \mathrm{cm}^{2}$ for H-rad (EDM \#6) and Welded \#1 samples at $80^{\circ} \mathrm{C}$.

The Bode phase angle plots in Figure 39b show a decrease in the phase angles with increasing temperature, irradiation levels, and mechanical processing (welding). Nyquist plots in Figures $39 \mathrm{c}$ and $39 \mathrm{~d}$ show that the surface became less capacitive with increasing irradiation levels at $80^{\circ} \mathrm{C}$. Figure $39 \mathrm{~d}$ is an enlarged Nyquist plot that shows the H-rad (EDM \#6) and Welded \#1 samples were the least capacitive, and therefore the least corrosion resistant. 


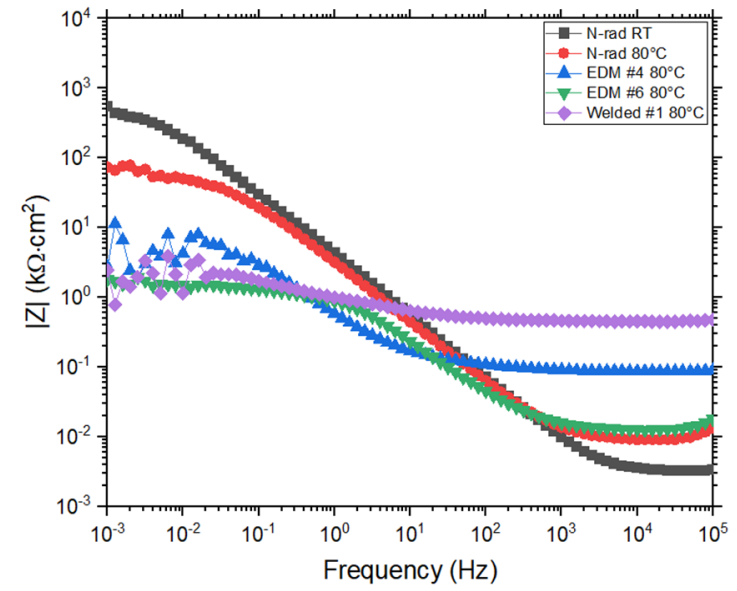

(a)

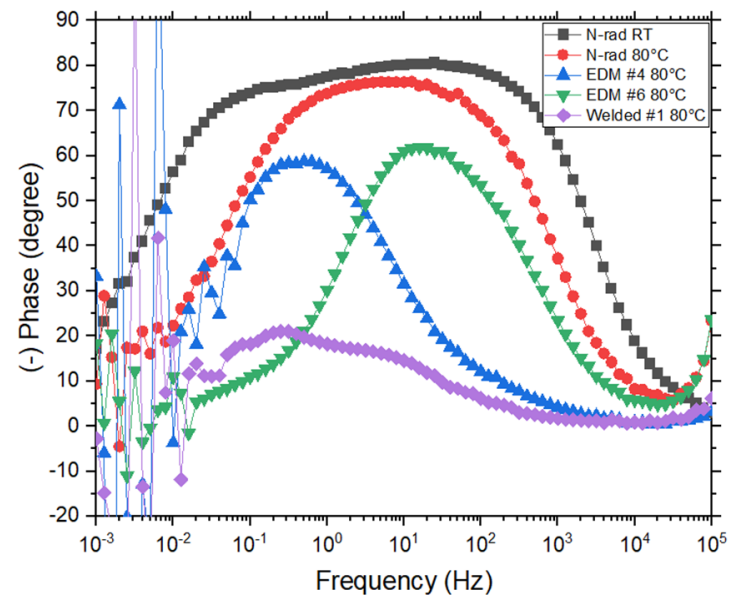

(b)

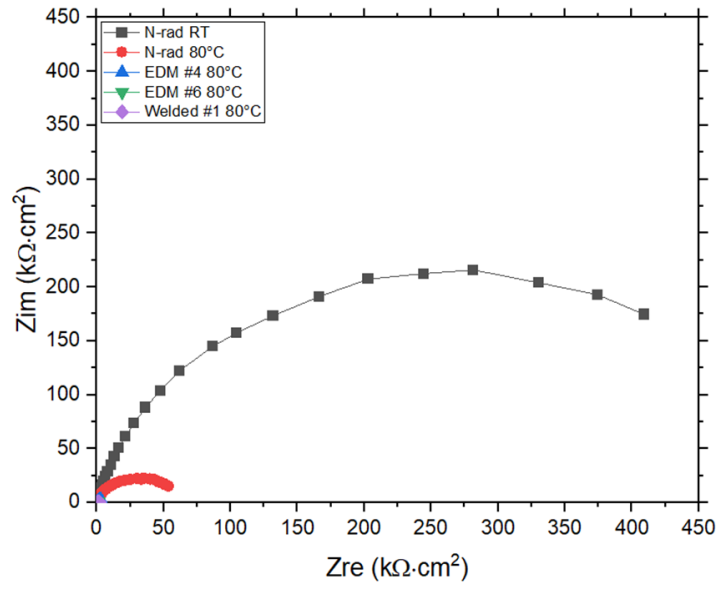

(c)

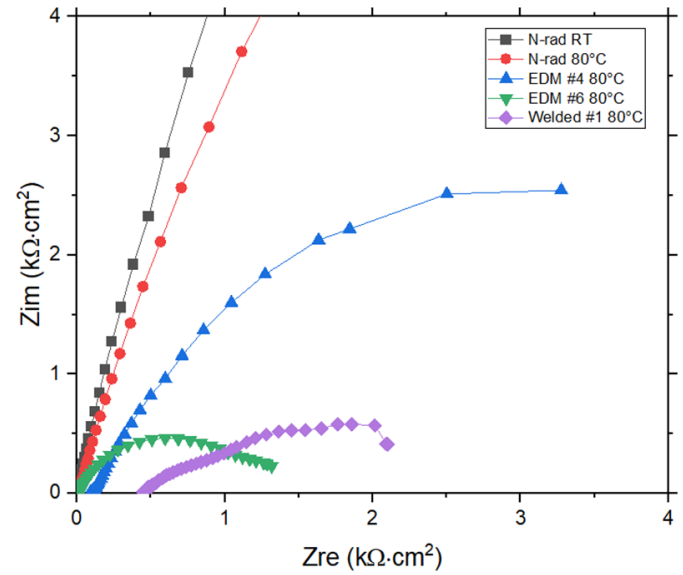

(d)

FIGURE 39 EIS curves after PS tests at $0.8 \mathrm{~V}_{\text {SCE }}$ with SS-347 samples at $80^{\circ} \mathrm{C}$ in $\mathrm{pH}=1 \mathrm{UO}_{2} \mathrm{SO}_{4}$ (dU = 200 g/L)solution: (a) Bode magnitude, (b) Bode phase angle, (c and d) Nyquist

\subsection{Corrosion Rates of SS-347 Samples}

The corrosion current monitored during the PS tests indicated interactions between the SS-347 material surface and the solution that can result in passivation or active corrosion of the material. In most cases, a steady current was achieved within a few hours to days and resulted in a constant corrosion rate. The steady current densities measured in the PS tests can be converted into mass corrosion rates using Faraday's Law, which relates the cumulative charge transferred through the working electrode to the mass of material oxidized (Equation 2):

$$
m=Q M / n F
$$

where $m$ is the mass of substance oxidized, $Q$ is the cumulative electric charge passed through the electrode substance, $M$ is the molecular weight of the electrode substance, $F$ is the Faraday constant, and $n$ is the number of electrons transferred. 
For a constant corrosion current, which is typically achieved during PS tests within a few days, the mass corroded over an interval $\Delta t$ can be calculated as:

$$
m=(I \cdot \Delta t M) / n F
$$

Where $I$ is the reaction current. The corrosion rate can be calculated as:

$$
\text { rate }=m / \Delta t=I M / n F
$$

where $m$ is the mass of substance oxidized. The current and mass released can be normalized to the surface area of the electrode to give corrosion rates in units of mils penetration per year (mpy), which can be used to calculate the service life of the SS-347 material. Tables 9 and 10 show the corrosion rates measured with SS-347 materials during the PS tests in $\mathrm{pH}=1 \mathrm{H}_{2} \mathrm{SO}_{4}$ and $\mathrm{UO}_{2} \mathrm{SO}_{4}(200 \mathrm{~g} / \mathrm{L})$ solutions, respectively.

The corrosion rates measured for as-received SS-347 samples in $\mathrm{pH}=1 \mathrm{H}_{2} \mathrm{SO}_{4}$ solution (Table 9) at RT increased with increase in the applied voltages, which indicates the surface oxide film was not very stable at higher redox potentials. However, the corrosion rates measured at a high redox of $0.8 \mathrm{~V}_{\mathrm{SCE}}\left(1.024 \mathrm{~V}_{\mathrm{SHE}}\right)$ were substantially lower $(<1 \mathrm{mpy})$, which indicates good corrosion properties for flat and bent (Bent \#0) samples. The corrosion rates measured at $80^{\circ} \mathrm{C}$ were approximately 10 times higher compared with RT $\left(25^{\circ} \mathrm{C}\right)$, which indicates the surface oxide film was not as protective.

TABLE 9 Corrosion rates measured in potentiostatic tests with SS-347 samples in $\mathrm{H}_{2} \mathrm{SO}_{4}$ solution

\begin{tabular}{lcccc}
\hline \multicolumn{1}{c}{ Sample } & Temperature & $\begin{array}{c}\text { Potential } \\
\left(\mathrm{V}_{\mathrm{SCE}}\right)\end{array}$ & $\begin{array}{c}\text { Current density } \\
\left(\mu \mathrm{A} \cdot \mathrm{cm}^{-2}\right)\end{array}$ & $\begin{array}{c}\text { Corrosion rate } \\
\left(\mathrm{mpy}^{*}\right)\end{array}$ \\
\hline As-received & $25^{\circ} \mathrm{C}$ & 0.5 & 0.04 & 0.017 \\
As-received & $25^{\circ} \mathrm{C}$ & 0.8 & 0.8 & 0.34 \\
As-received & $25^{\circ} \mathrm{C}$ & 1.0 & 700 & 297 \\
N-rad (EDM \# $\#)$ & $80^{\circ} \mathrm{C}$ & 0.8 & 11 & 4.7 \\
\hline Bent $\# 0^{*}$ & $25^{\circ} \mathrm{C}$ & 0.8 & 0.7 & 0.29 \\
\hline *mpy = mils per year $\left(10^{-3}\right.$ inches per year); EDM $\# 0=$ EDM nonirradiated; Bent \#0=bent nonirradiated
\end{tabular}

The corrosion behavior measured for as-received SS-347 samples in $\mathrm{UO}_{2} \mathrm{SO}_{4}$ solution (Table 10) at RT was similar to that of the SS-347 samples in $\mathrm{H}_{2} \mathrm{SO}_{4}$ solution, but the corrosion rates were lower. The corrosion rates measured at $80^{\circ} \mathrm{C}$ were approximately 10 times higher than at RT, which again indicates the surface oxide film was not as protective. The corrosion rates measured at $0.8 \mathrm{VSCE}$ and $80^{\circ} \mathrm{C}$ were higher for samples irradiated at higher dose rates and total accumulated dose. 
The corrosion rates increased by 10 times between N-rad and H-rad samples. This shows the negative effect of irradiation on corrosion performance. The corrosion rates measured for $\mathrm{H}$-rad were higher than the desirable rate of $\sim 1 \mathrm{mpy}$, which is required to maintain good corrosion performance for alloy materials.

TABLE 10 Corrosion rates measured in PS tests with SS-347 samples in $\mathrm{UO}_{2} \mathrm{SO}_{4}$ solution

\begin{tabular}{|c|c|c|c|c|c|c|}
\hline Sample & $\begin{array}{l}\text { Dose Rate } \\
(\mathrm{Mrad} / \mathrm{min})\end{array}$ & $\begin{array}{l}\text { Total } \\
\text { Dose } \\
\text { (Grad) }\end{array}$ & Temperature & $\begin{array}{c}\text { Potential } \\
\left(\mathrm{V}_{\mathrm{SCE}}\right)\end{array}$ & $\begin{array}{c}\text { Current } \\
\text { density } \\
\left(\mu \mathrm{A} \cdot \mathrm{cm}^{-2}\right)\end{array}$ & $\begin{array}{l}\text { Corrosion } \\
\text { rate }\left(m p y^{*}\right)\end{array}$ \\
\hline As-received & - & - & RT & 0.5 & 0.025 & 0.011 \\
\hline As-received & - & - & RT & 0.8 & 0.3 & 0.13 \\
\hline As-received & - & - & RT & 1.0 & 450 & 191 \\
\hline Welded \#1 & & & $80^{\circ} \mathrm{C}$ & 0.8 & 35 & 14.8 \\
\hline $\mathrm{N}-\operatorname{rad}\left(\mathrm{EDM} \# 0^{*}\right)$ & - & - & $80^{\circ} \mathrm{C}$ & 0.8 & 2.6 & 1.10 \\
\hline M-rad (EDM \#4) & 14.03 & 11.6 & $80^{\circ} \mathrm{C}$ & 0.8 & 6 & 2.6 \\
\hline H-rad (EDM \#6) & 56.13 & 47.2 & $80^{\circ} \mathrm{C}$ & 0.8 & 29 & 12.8 \\
\hline
\end{tabular}

$*_{\text {mpy }}=$ mils per year $\left(10^{-3}\right.$ inches per year $) ;$ EDM \#0 = EDM nonirradiated 


\section{SUMMARY AND CONCLUSIONS}

We assessed the electrochemical corrosion performance of as-received, bent, welded, and irradiated SS-347 materials under a range of redox conditions that could occur during Mo-99 production. The electron microscopy and corrosion tests were conducted in $\mathrm{H}_{2} \mathrm{SO}_{4}$ and $\mathrm{UO}_{2} \mathrm{SO}_{4}$ solutions at $\mathrm{RT}$ and $80^{\circ} \mathrm{C}$.

The FE-SEM secondary electron images of the polished and etched SS-347 samples showed bright, small $\mathrm{NbC}$ (carbide precipitates) in the austenitic matrix. Energy dispersive X-ray spectroscopy spot analyses of the surface showed the austenitic matrix was rich in $\mathrm{Fe}, \mathrm{Cr}$, and Ni.

OCP was monitored for 28 days in $\mathrm{pH}=1 \mathrm{H}_{2} \mathrm{SO}_{4}$ solution at $\mathrm{RT}$ to assess the surface passivation under freely corroding conditions. The OCP profile showed that the surface passivated initially to a stable value ( $0.06 \mathrm{VSCE})$. However, significant potential drops were observed after 15 and 22 days, possibly due to preferential corrosion of the matrix around the precipitates ( $\mathrm{Nb}$ carbides). EIS results showed a quick establishment of passivity with highly capacitive surface passive layer. These results also showed a typical diffusion behavior (Warburg effect) due to carbide corrosion on the surface. However, the new bare surface that formed due to carbide corrosion repassivated.

PD scans were used to identify corrosion characteristics, including ECORR and ICORR values and active, passive, and transpassive regions. The PD scans of as-received SS-347 samples were conducted in $\mathrm{pH}=1 \mathrm{H}_{2} \mathrm{SO}_{4}$ and $\mathrm{UO}_{2} \mathrm{SO}_{4}(200 \mathrm{~g} / \mathrm{L})$ solutions at $\mathrm{RT}$ and at $80^{\circ} \mathrm{C}$. The ECORR measured during the PD scan in the $\mathrm{UO}_{2} \mathrm{SO}_{4}$ solution was about $215 \mathrm{mV}_{\text {SCE }}$ higher than measured in $\mathrm{H}_{2} \mathrm{SO}_{4}$ solution at RT. The corrosion currents measured in the passive region were about 4-5 times higher in the $\mathrm{UO}_{2} \mathrm{SO}_{4}$ solution. The transpassive regions of both PD scans were identical and both samples did not show any significant corrosion at RT.

The PD scans of the as-received samples in $\mathrm{pH}=1 \mathrm{H}_{2} \mathrm{SO}_{4}$ and $\mathrm{UO}_{2} \mathrm{SO}_{4}(200 \mathrm{~g} / \mathrm{L})$ solutions at $80^{\circ} \mathrm{C}$ showed reductions in the passive voltage range and lower transpassive potentials compared with PD scans at RT. The corrosion current densities in the transpassive regions in both solutions increased significantly when exposed to $80^{\circ} \mathrm{C}$. The microstructures after PD scans showed significant pitting corrosion damage in the sample exposed to $\mathrm{H}_{2} \mathrm{SO}_{4}$. However, less corrosion damage was observed on the sample tested in $\mathrm{UO}_{2} \mathrm{SO}_{4}$ solution at $80^{\circ} \mathrm{C}$.

The PD scans conducted with as-received, bent, and welded SS-347 samples in $\mathrm{UO}_{2} \mathrm{SO}_{4}$ solution at $80^{\circ} \mathrm{C}$ showed the effects of mechanical deformation on the corrosion behaviors. The bent sample had lower ECORR and higher corrosion current densities compared with the asreceived and welded samples. The mechanical bending reduced the corrosion resistance, and the SEM microstructures showed extensive intergranular and pitting corrosion. While ECORR for the welded sample was similar to the as-received sample, the welded sample did not show a welldefined passive region, likely due to residual stresses and different microstructures that could have been generated after welding. The PD scans indicate that the corrosion resistance for the 
welded and bent regions would be lower under high redox conditions generated during Mo-99 production.

PS tests were conducted with nonirradiated and irradiated SS-347 samples at RT and $80^{\circ} \mathrm{C}$ in $\mathrm{pH}=1 \mathrm{H}_{2} \mathrm{SO}_{4}$ and $\mathrm{pH} 1=1 \mathrm{UO}_{2} \mathrm{SO}_{4}$ solutions. The currents measured in the PS tests conducted in the passive region $(0.5$ and $0.8 \mathrm{VSCE})$ at RT stabilized within 24 hours and remained stable for the duration of the test in both solutions. The results indicate quick passivation of the surface and high corrosion resistance of the passive layer. It is also observed that the corrosion currents increase at higher voltages (redox). As expected, extremely high corrosion currents were measured in the PS tests in the transpassive region $\left(1.0 \mathrm{~V}_{\mathrm{SCE}}\right)$. The EIS results confirm that the surface passive layer is highly capacitive throughout the passive region. Poor surface electrical properties with no passive layer were measured on the surface in the transpassive region.

PS tests were also conducted to assess the effects of temperature. The corrosion currents measured for the as-received sample at $80^{\circ} \mathrm{C}$ in $\mathrm{H}_{2} \mathrm{SO}_{4}$ solution were an order of magnitude higher than at RT. The SEM images showed significant intergranular corrosion with pitting on the austenitic matrix grains after the PS test at $80^{\circ} \mathrm{C}$. The corrosion currents measured with $\mathrm{N}$-rad (EDM machined and nonirradiated) samples at $80^{\circ} \mathrm{C}$ in $\mathrm{UO}_{2} \mathrm{SO}_{4}$ solution were an order of magnitude higher compared those measured at RT. The SEM after the PS test with N-rad sample at $80^{\circ} \mathrm{C}$ showed a thick and brittle surface passive layer, which is not as protective. Hence, the corrosion resistance decreases with increase in temperature.

PS tests measured the effects of irradiation on corrosion performance in two N-rad samples and two samples with different levels of irradiation: M-rad (mild, EDM \#4) and H-rad (high, EDM \#6) and one welded (Welded \#1) sample. The corrosion current densities measured at $0.8 \mathrm{VSCE}$ (oxidizing redox condition) in $\mathrm{UO}_{2} \mathrm{SO}_{4}$ solution at $\mathrm{RT}$; at $80^{\circ} \mathrm{C}$, it showed the Welded\#1 and H-rad samples had the highest current densities followed by the M-rad and N-rad samples. SEM images after PS tests on the M-rad, H-rad, and Welded \#1 surfaces showed localized pitting and thick localized surface oxides.

The corrosion currents measured in the PS tests showed a systematic effect of temperature and irradiation level on corrosion performance. Long-term corrosion rates were calculated using the stable corrosion current values measured in the PS tests.

The corrosion rates measured for SS-347 samples at $80^{\circ} \mathrm{C}$ in $\mathrm{UO}_{2} \mathrm{SO}_{4}$ solution were approximately 10 times higher than at RT, which indicates the surface oxide film was not as protective. Higher corrosion rates were measured with increases in solution redox potentials. However, the corrosion rates measured at high redox of $0.8 \mathrm{~V}_{\mathrm{SCE}}\left(1.024 \mathrm{~V}_{\mathrm{SHE}}\right)$ were substantially lower ( $<1 \mathrm{mpy})$, which indicates good corrosion properties.

PS tests showed high corrosion rates at $0.8 \mathrm{~V}_{\mathrm{SCE}}$ in $\mathrm{UO}_{2} \mathrm{SO}_{4}$ solution at $80^{\circ} \mathrm{C}$ for samples irradiated at high dose rates and high total accumulated dose. The corrosion rates increased by 10 times between $\mathrm{N}$-rad (nonirradiated) and welded (Welded \#1, dose rate $139.9 \mathrm{Mrad} / \mathrm{min}$, total dose $96.55 \mathrm{Grad}$ ) H-rad (EDM \#6, dose rate $56.13 \mathrm{Mrad} / \mathrm{min}$, total dose $47.2 \mathrm{Grad}$ ) samples. EIS results confirmed the surfaces were less corrosion resistant at the elevated temperature of $80^{\circ} \mathrm{C}$ and the impedance of the surface oxide layer dropped to very low values for Welded \#1 
and H-rad samples. This shows the detrimental impact of irradiation on corrosion performance. The corrosion rate measured for Welded \#1 was 14.8 mpy and H-rad was 12.8 mpy, higher than the desirable rate of $\sim 1 \mathrm{mpy}$, which is required to maintain good corrosion performance for alloy materials. Corrosion rates are higher in welded regions and are expected to be higher in the bent regions compared to flat regions due to mechanical deformation and residual stresses in the alloy. Furthermore, irradiation will accelerate the corrosion due to radiolysis and other mechanisms that would alter the local redox $(\mathrm{Eh}>0.8 \mathrm{VSCE})$ conditions during the acceleratorbased production of fission-made Mo-99. 


\section{REFERENCES}

[1] D. Wu, S. Landsberger, B.A. Buchholz, and G.F. Vandegrift, Processing of LEU Targets for Mo-99 Production-Testing and Modification of the Cintichem Process, 1995 International Meeting on Reduced Enrichment for Research and Test Reactors, Paris, France, September 18-21, 1994, www.rertr.anl.gov/MO99/WU95.pdf.

[2] Z. Aliludin, A. Mutalib, A. Sukmana, Kadarisman, A.H. Gunawan, G.F. Vandegrift. D. Wu, B. Srinivasan, and J. L. Snelgrove, Processing of LEU Targets for Mo-99 Production-Demonstration of a Modified Cintichem Process, 1995 International Meeting on Reduced Enrichment for Research and Test Reactors, Paris, France, September 18-21, 1994, www.rertr.anl.gov/MO99/BATAN95.pdf.

[3] D. Wu, S. Landsberger, and G.F. Vandegrift, Progress in Chemical Treatment of LEU Targets by the Modified Cintichem Process, 1996 International Meeting on Reduced Enrichment for Research and Test Reactors, Seoul, Korea, October 7-10, 1996, https://www.rertr.anl.gov/PAPERS96.html

[4] R.A. Leonard, L. Chen, C.J. Mertz, and G.F. Vandegrift, Progress in Dissolving Modified LEU Cintichem Targets, 1996 International Meeting on Reduced Enrichment for Research and Test Reactors, Seoul, Korea, October 7-10, 1996, https://www.rertr.anl.gov/PAPERS96.html

[5] A. Bakel., A. Leyva, T. Wiencek, A. Hebden, K. Quigley, J. Falkenberg, L. Hafenrichter, and G. Vandegrift, Overview of Progress Related to Implementation of the LEU-Modified Cintichem Process, 2008 International RERTR Meeting, Washington, D.C., October 5-9, 2008, www.rertr.anl.gov/RERTR30/pdf/S8-1_Bakel.pdf.

[6] T. Brossard, J. Byrnes, P. Tkac, Conversion of Uranium Metal to Uranyl Sulfate Solution, Argonne National Laboratory Report, ANL-20/18, March 2020.

[7] J.L. Jerden, SHINE Target-Solution Chemistry: Thermodynamic Modeling of Speciation, Precipitate Formation, and the Chemical Effects of Stainless Steel Corrosion, ANL/CSE-14/11, Argonne National Laboratory, 2014.

[8] MCNP official page: https://mcnp.lanl.gov/.

[9] J.F. Ziegler, Interaction of Ions with Matter, website, www.srim.org.

[10] T.T. Böhlen et al., The FLUKA Code: Developments and Challenges for High Energy and Medical Applications, Nuclear Data Sheets 120: 211-214, 2014.

[11] J. Verbeke, C. Hagmann, D. Wright, Simulation of Neutron and Gamma Ray Emission from Fission and Photofission, UCRL-AR-228518, April 11, 2010, www.researchgate.net/publication/228390042. 
[12] J. Katakura, T.R. England, Augmentation of ENDF/B Fission Product Gamma-Ray Spectra by Calculated Spectra, LA-12125-MS, ENDF-352, Lawrence Livermore National Laboratory, 1991, www.osti.gov/servlets/purl/6384311.

[13] E.T. Journey, P.J. Bendt, T.R. England, Fission Product Gamma Spectra, LA-7620-MS, Jan. 1979, https://inis.iaea.org/collection/NCLCollectionStore/_Public/10/454/ 10454100.pdf.

[14] F.T. Avignone III, L.P. Hopkins, Z.D. Greenwood (1979) Theoretical Beta Spectrum from Uranium-235 Fission Fragments in Secular Equilibrium, Nuclear Science and Engineering 72:2, pp. 216-221, 1979, DOI: 10.13182/NSE79-A19465. 



\section{Argonne}

\section{Chemical \& Fuel Cycle Technologies Division}

Argonne National Laboratory

9700 South Cass Avenue, Bldg. 205

Lemont, IL 60439-4832

www.anl.gov 